\title{
Cardioversion of recent-onset atrial fibrillation and flutter in the emergency department
}

\author{
Acil serviste yeni başlangıçlı atriyal fibrilasyon ve flutter kardiyoversiyonu \\ Osman Beton*, Mehmet Birhan Yılmaz, Özge Korkmaz, Öcal Berkan, İzzet \\ Tandoğan
}

Department of Cardiology (Assist. Prof. O. Beton, MD, Prof. M. B. Y1lmaz, MD, Prof. İ. Tandoğan, MD), Department of Cardiovascular Surgery (Assist. Prof. Ö. Korkmaz, MD, Prof. Ö. Berkan, MD), Cumhuriyet University Medical of School, TR-58140 Sivas

\begin{abstract}
Atrial fibrillation (AF) is the most common arrhythmia encountered in acute medical practice. One-third of hospitalizations for cardiac rhythm disturbances are attributed to AF, with increasing rates in the past decade. Significant morbidity and mortality, including $15 \%$ to $20 \%$ of all ischemic strokes and $20 \%$ of all strokes, result from AF. The overall mortality rate for patients with AF is approximately double that for patients in normal sinus rhythm. Atrial flutter (AFL) has many clinical aspects that are similar to AF, AF and AFL have same management strategies in emergency settings. The major goals of treatment include alleviation of the associated symptoms and/or hemodynamic disturbance, reduction of the risk of systemic thromboembolism, reduction in hospital length of stay. The very large scaled AFFIRM and AF-CHF clinical trials compared rate and rhythm control (cardioversion), but did not explore the optimal management for recent-onset AF/AFL patients presenting to the emergency department (ED) with in 48 hours of symptoms. Although international standard guidelines are available, AF treatment in ED is still heterogeneous in terms of the management strategy (rate or rhythm) chosen. National based guidelines or consensus documents specific to ED management of AF has recently been developed and published in order to solve this problem. Aim of this review is to give detailed information for ED team about echocardiographic criterias supporting cardioversion (CV) of AF, CV procedure itself and new antiarrhythmic and oral anticoagulant drugs by adhering to the guidelines.
\end{abstract}

Keywords: Cardioversion, recent-onset atrial fibrillation, flutter, emergency

\section{Özet}

Atriyal fibrilasyon, akut tıbbi uygulamada karşılaşılan en sık aritmidir. Kalp ritm bozuklukları nedeniyle hastaneye yatanların üçte birinde neden AF olup son on yılda sıklığı giderek artmaktadır. AF belirgin mortalite ve morbiditeye neden olmaktadır. Tüm iskemik inmelerin \%15\%20'si ve tüm inmelerin \%20'si AF nedenlidir. AF'si olan hastalarda genel ölüm oranı, normal sinus ritmi olanlara göre yaklaşık iki kat fazladır. Atriyal flutter (AFL)'in AF'e benzer birçok klinik yönleri bulnumaktadır, acil durumlarda AF ve AFL aynı tedavi stratejilerine sahiptir. Tedavinin başlıca hedefleri, ilgili semptom ve/veya hemodinamik bozukluğun azaltılması, sistemik tromboembolik riskin azaltılması ve hastanede kalış süresinin kısaltılmasını içermektedir. Çok büyük ölçekli AFFIRM ve AF-CHF çalışmaları, hız ve ritim kontrolü (kardiyoversiyon) stratejilerini kıyasladı, fakat, semptom başlangıcının 48 saati içerisinde acile servise(AS) başvuran, yeni başlangıçlı AF/AFL hastalarında optimal tedavi yöntemini açığa kavuşturamadı. Uluslararası standart kılavuzlar bulunmasına rağmen AS'de AF tedavisi, seçilen tedavi stratejisi (hız veya ritim) yönünden hala heterojendir. Son zamanlarda bu sorunu çözmek amaciyla, AS'de AF tedavisine yönelik ulusal kaynaklı kılavuzlar ve konsensüs belgeleri geliştirilmiş ve yayınlanmıştır. Bu derlemenin amacı, AS ekibine, kılavuzlara bağlı kalınarak kardiyoversiyonu destekleyen ekokardiyografik parametreler, kardiyoversiyon işleminin kendisi ve yeni antiaritmik ve antikoagulan ilaçlar hakkında ayrıntılı bilgi sunmaktır.

Anahtar sözcükler: Kardiyoversiyon, atrial fibrilasyon, flutter, acil 
Geliş tarihi/Received: July 13, 2013; Kabul tarihi/Accepted: May 20, 2014

\section{*Corresponding author:}

Dr. Osman Beton, Kardiyoloji Anabilim Dalı, Cumhuriyet Üniversitesi Tıp Fakültesi, TR-58140 Sivas. E-mail: obeton@ cumhuriyet.edu.tr

\section{Introduction}

Atrial fibrillation (AF) is the most common arrhythmia encountered in acute medical practice, occurring in 3.3\%-10\% of emergency admissions [1-4]. In some of these cases, $\mathrm{AF}$ is longstanding and/or incidental to clinical management, but more often AF has developed acutely as either the primary clinical problem or as a complication of another acute (pneumonia, myocardial infarction, septicaemia, pulmonary embolism, exacerbations of chronic obstructive pulmonary disease etc) or chronic (valvular heart disease, hypertension, heart failure, cardiomyopathies, etc) diseases. One-third of hospitalizations for cardiac rhythm disturbances are attributed to AF, with increasing rates in the past decade. Significant morbidity and mortality, including $15 \%$ to $20 \%$ of all ischemic strokes and $20 \%$ of all strokes, result from AF. Patients with nonvalvular AF have $5 \%$ average risk of ishemic stroke per year which is 2 to 7 times of the population without AF. The overall mortality rate for patients with AF is approximately double that for patients in normal sinus rhythm (SR) [5, 6]. AF has increasing prevalance and negative impact on quality of life and health care expences. AF is associated with many causes and comorbidities [5, 6]. Atrial flutter (AFL) has many clinical aspects that are similar to AF (ie, underlying disease, predisposing factors, complications, medical management), AF and AFL have same management strategies in emergency settings.

In the emergency department (ED), physicians often manage patients with either recentonset [first detected or recurrent (presence of $\geq 2$ episodes)] or those with permanent AF/AFL. However, it may not be possible to differentiate between a self-limiting attack of "paroxysmal AF" (expected to convert spontaneously to SR within 7 days), or the onset of "persistent AF" (sustained beyond 7 days or SR will only be restored by electrical or pharmacological cardioversion (CV)) if this is the patient's first episode [58]. The major goals of treatment include alleviation of the associated symptoms and/or hemodynamic disturbance, reduction of the risk of systemic thromboembolism, reduction in hospital length of stay. For clinicians, determining management in individual cases can appear complex and confusing because the available therapeutic options include electrical CV (immediate or interval) with or without maintenance antiarrhythmic drugs OR pharmacological $\mathrm{CV}$ with intravenous or oral agents OR pharmacological rate-control AND anticoagulation (parenteral or oral) according to guidelines. In the case of permanent AF/AFL or long-standing persistant AF/AFL ( $>1$ year) which usually leads to permanent $\mathrm{AF}, \mathrm{CV}$ has previously failed or clinical judgment has led to a decision not to pursue $\mathrm{CV}$, ED management focuses on rate control, anticoagulation and treatment of underlying conditions. Management strategies for recent-onset paroxysmal or persistent AF/AFL includes anticoagulation and rate or rhythm control [5-8]. The very large scaled AFFIRM and AF-CHF clinical trials compared rate and rhythm control, but did not explore the optimal management for recent-onset AF/AFL patients presenting to the ED with in 48 hours of symptoms [9-10]. Although international standard guidelines are available, AF treatment in ED is still heterogeneous in terms of the management strategy chosen [11-17]. According to results of many clinical trials showing disparities in management of AF in ED, national based guidelines or consensus documents specific to $\mathrm{ED}$ management of AF has recently been developed and published in order to solve this problem [18-19]. Inspite of the fact that these guidelines are good guidance to clinical practice, information about patient's echocardiographic suitability criterias to CV and CV procedure itself are not well described. Aim of this review is to give detailed information 
for ED team about echocardiographic criterias supporting $\mathrm{CV}, \mathrm{CV}$ procedure itself and new antiarrhythmic and oral anticoagulant drugs by adhering to the guidelines.

\section{Current approach for the management of $A F / A F L$}

The main goals of AF/AFL management are shown in Figure 1: Identify and treat underlying structural heart disease and other etiological conditions (Table 1), alleviate symptoms, improve functional capacity and quality of life and reduce morbidity/mortality associated with AF/AFL by preventing tachycardia-induced cardiomyopathy, stroke or thromboembolism and ED visits and hospitalizations [5-8].

\section{Antithrombotic prophylaxis treatment in AF}

AF/AFL favors the formation of intra-atrial thrombi, which can break off and cause thromboembolism, the most serious and frequent being cerebral embolism causing stroke. The risk of stroke in AF/AFL is much higher when associated with valvular heart diseases (rheumatic, prosthetic, etc.) and increases particularly after $\mathrm{CV}$, whether spontaneous, pharmacological or electrical especially when AF/AFL is prolonged before CV. Prophylactic antithrombotic agents substantially decrease the risk of stroke in AF/AFL. There are three different clinical situations: Non-valvular AF, AF associated with a prosthetic valve or rheumatic/ degenerative/myxamatous (especially mitral) valve diseases, and $\mathrm{CV}$ of $\mathrm{AF}$ regarding individual recommendations for antithrombotic prophylaxis $[6-8,19,20]$.

The incidence of stroke in non-valvular AF is $4-5 \%$ globally per year, but varies greatly with the thromboembolic risk factors involved. Thromboembolic risk score CHA2DS2VASc is the best known and practical and recommended by guidelines (Table 2) [20]. Of these risk factors, the most important is a history of stroke, TIA or systemic arterial embolism, with a relative risk of 2.5 to 2.9 and an annual incidence of stroke of $12 \%$. Advanced age is second in importance. It is estimated that as from the age of 65 years, the relative risk of developing thromboembolic events increases each decade from 1.4 to 1.8 $[19,20]$ If total $\mathrm{CHA}_{2} \mathrm{DS}_{2}$-VASc risk score is calculated as 9 , there is $15.2 \%$ annual adjusted stroke rate risk. Antithrombotic therapy according to $\mathrm{CHA}_{2} \mathrm{DS}_{2}-\mathrm{VASc}$ risk score is shown in Figure 2 through recommendation by updated 2012 ESC guideline [20]. Decision-making for thromboprophylaxis needs to balance the risk of stroke against the risk of major bleeding, especially intracranial hemmorrhage, which is the most feared complication of anticoagulation therapy and confers a high risk of death and disability. HAS-BLED score which is a formal bleeding risk assessment (Table 3 ) is recommended for all patients with $\mathrm{AF}$, and in patients with a HAS-BLED score $\geq 3$, caution and regular review are appropriate, as well as efforts to correct the potentially reversible risk factors for bleeding. HAS-BLED score should not be used to exclude patients from oral anticoagulant (OAC) therapy but allows clinicians to make an informed assessment of bleeding risk and, importantly, makes them think of the correctable risk factors for bleeding $[6,20]$. Target international normalized ratio (INR) is between 2.0 to 3.0 in nonvalvular AF patients anticoagulated with vitamine $\mathrm{K}$ antagonists (VKAs) [20].

The incidence of stroke in patients with $\mathrm{AF}$ and mechanical prosthetic valves or valvular heart diseases [rheumatic/degenerative/myxamatous (especially mitral valve diseases)] is about $17 \%$. Thereby, AF requires life-long anticoagulation therapy in patients with valvular heart disease. VKAs (Acenocoumarol, warfarin, phenprocoumon) are the only drugs approved for thromboprophylaxis in these patients $[21,22]$ Target INR is between 2.0-3.0 in patients valvular heart (except prosthesis) disease with $\mathrm{AF}[21,22]$. Recommended level of anticoagulation (INR level) in patients with prosthetic valves in the presence of AF is summarized in Table 4 [21, 22]. In ESC/EACTS guideline, the addition of aspirin 75 to $100 \mathrm{mg}$ once daily to therapeutic warfarin is recommended for all patients with mechanical heart valves and those patients with biological valves ( e.g. bioprosthesis) who have risk factors (AF, previous thromboembolism, LV dysfunction $\mathrm{EF}<35 \%$ and hypercoagulable condition) [21]. But in ACC/AHA guideline addition of 
low-dose aspirin should be considered in patients with a mechanical prosthesis and concomitant atherosclerotic disease or after thromboembolism despite adequate INR [22].

The pro-embolic tendency increases markedly after CV, if it is spontaneous or pharmacological or electrical, especially when the period of $\mathrm{AF}$ before $\mathrm{CV}$ is prolonged $[23,24]$. After $\mathrm{CV}$, risk of thrombo-embolism due to post-CV left atrial/left atrial appendage (LAA) dysfunction (so-called 'atrial stunning') persists up to 3 months [25]. Anticoagulation in pre-CV and post-CV periods is crucial and discussed more detailed later in the passage.

\section{Arrhyhtmia management strategies in AF}

Two different strategies exist for the management of cardiac rhythm in patients with AF. The first entails allowing AF to persist while ventricular rate is controlled. The second is CV and attempting to maintain SR with antiarrhythmic drugs (Figure 1) [26]. Goals of the both strategies are to alleviate symptoms, improve functional capacity and quality of life and reduce morbidity/mortality associated with $\mathrm{AF} / \mathrm{AFL}$ by preventing tachycardiainduced cardiomyopathy and reduce hospitalization/admission rates [5-8].

Heart rate control strategy aims to maintain a ventricular rate that protects the patient from consequences of tachycardia. Target ventricular rate control in the absence of accessory pathway (pre-excitation syndrome) can be obtained by atriventricular nodal conduction slowing drugs (Table 5). Initial target ventricular rate is $<100 \mathrm{bpm}$ at rest (lenient rate). If complaints persist despite lenient rate achievement, strict rate control ( $<80 \mathrm{bpm}$ at rest and $<110 \mathrm{bpm}$ during moderate exercise) should be substituted. In case of failure to obtain target ventricular heart rate with drug therapy, atriventricular node ablation and pacemaker implantation can be considered or SR restoration (rhythm control) can be attempted in the presence of supportive clinical and echocardiographic factors (Table 6) [6, 18-20].

Rhythm control strategy targets SR restoration by pharmacological CV (antiarrhythmic drugs) \pm electrical CV and maintenance by antiarrhythmic drugs (Table 7). This strategy is usually considered for patients with paroxsymal or persistant $\mathrm{AF}$ in the presence of favourable clinical and echocardiographic parameters (Table 6) $[7,8,19,20]$. These parameters predict high possibility of staying in SR after CV.

AFFIRM and AF-CHF clinical trials compared rate and rhythm control did not demonstrate significant difference in terms of mortality and morbidity [9-10]. In clicinal practice, it is more practical and easy to choose rate control strategy for physicians [11, 12]. But it should not be forgotten that these trials did not explore the optimal management for recent-onset AF/AFL patients presenting to the ED with in 48 hours of symptoms. Besides that current guidelines recommend rhythm control as a first line strategy for resent onset AF and suggest not considering heart rate control strategy as an alternative to exclusive control of the rhythm in patients with favourable clinical and echocardiographical factors for attemping SR restoration [6, 18-20].

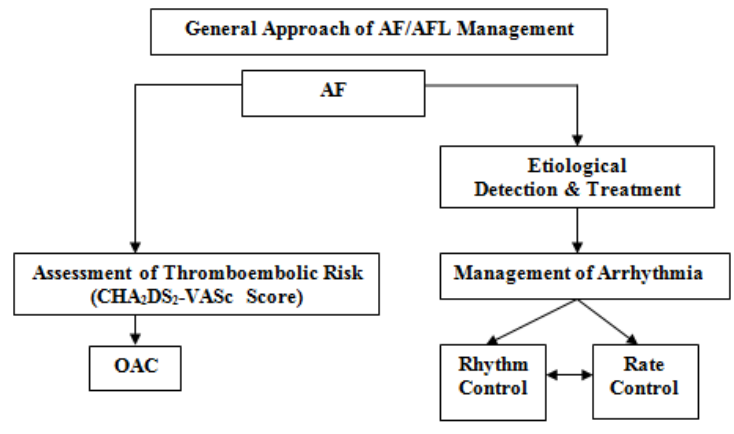

Figure 1. Overview of AF management. If a strategy of rate or rhythm control is not successful, crossover to the alternate strategy may be required. AF, atrial fibrillation; OAC, oral anticoagulation; CHA2DS2-VASc Score, in Table 2 and Figure 2. 
Table 1. Etiology of AF and AFl.

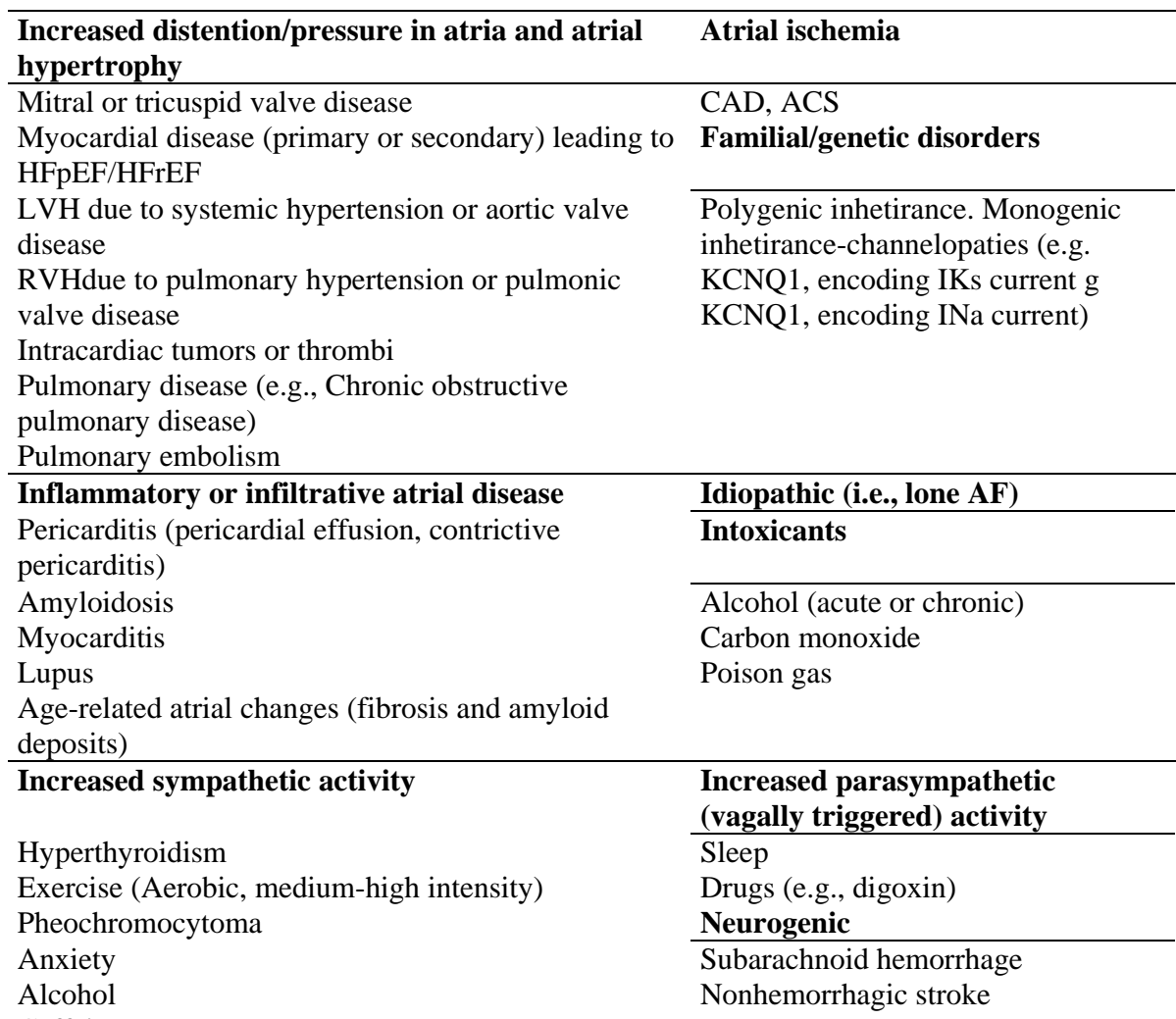

Caffeine

Sympathomimetic drugs (e.g., theophylline)

Heart failure

Pulmonary embolism

Post-cardiac surgery or post-throcic surgery

Inotropes (e.g., norepinephrine, epinephrine, levosimendan)

\title{
Congenital heart disease
}

Atrial septal defect

Ebstein's anomaly

Patent ductus arteriosus

After surgical correction of TOF, VSD, TGA

\author{
Systemic/metabolic/infection/others \\ Hypovolemia \\ Fever or hypothermia \\ Anemia \\ Electrolyte disorders \\ Diabettes mellitus
}

Acute infections (e.g., pneumonia,septicaemia) Obesity

Electrocution

\begin{tabular}{ll}
\hline Coexisting other cardiac arrhythmias & $\begin{array}{l}\text { Primary or metastatic cancer in or } \\
\text { adjacent to the atrial wall }\end{array}$ \\
$\begin{array}{l}\text { Atrioventricular nodal reentrant tachycardia } \\
\text { Atrioventricular reentrant tachycardia (Orhodromic, } \\
\text { antidromic/WPW) }\end{array}$ & $\begin{array}{l}\text { Lung carcinoma } \\
\text { Atrial tachycardia (e.g., focal) }\end{array}$ \\
Sick sinus syndrome & Mediastinal tumors \\
\end{tabular}

ACS; acute coronary syndromes, CAD; coronary artery disease, HFpEF; heart failure with preserved ejection fraction, HFrEF; heart failure with reduced ejection fraction, LVH; left ventricular hypertrophy, RVH; right ventricular hypertrophy, TGA; transposition of great arteries, TOF; tetralogy of Fallot, VSD; ventricular septal defect, WPW; Wolff-ParkinsonWhite. 
Table 2. CHA2DS2-VASc thromboembolic risk scoring scheme.

\begin{tabular}{lc}
\hline Risk factors & Score \\
\hline C Cardiac failure, left ventricular dysfunction $(<40 \%)$ & 1 \\
H Hypertension & 1 \\
A Age $\geq 75$ & 2 \\
D Diabetes mellitus & 1 \\
S Sroke or TIA or systemic thromboembolism & 2 \\
V Vascular artery disease: Myocardial infarction, peripheral arterial diease or complicated aortic plaque & 1 \\
A Age $\geq 65-<75$ & 1 \\
Sc Sex category: Female & 1 \\
\hline TIA: Transient ischemic attact &
\end{tabular}

Table 3. Clinical characteristics comprising the HAS-BLED bleeding risk score [6].

\begin{tabular}{|c|c|}
\hline Clinical characteristics $^{\mathrm{a}}$ & Score \\
\hline H Hypertension (uncontrolled) & 1 \\
\hline Abnormal liver or renal funtions (1 point each) & 1 or 2 \\
\hline Stroke & 1 \\
\hline Bleeding & 1 \\
\hline Labile INRs & 1 \\
\hline Elderly (age>65) & 1 \\
\hline D Drugs (aspirin, clopidogrel, NSAIs, etc) or alcohol ( 1 point each) & 1 or 2 \\
\hline \multicolumn{2}{|c|}{$\begin{array}{l}(\text { a). "Hypertension" is defined as systolic blood pressure } 160 \mathrm{mmHg} \text {. "Abnormal kidney } \\
\text { function" is defined as the presence of chronic dialysis or renal transplantation or serum } \\
\text { creatinine } \geq \mathbf{2 0 0} \mathrm{mmol} / \mathrm{L} \text { or } \geq 2.2 \mathrm{mg} / \mathrm{dL} \text {. "Abnormal liver function" is defined as chronic } \\
\text { hepatic disease (e.g cirrhosis) or biochemical evidence of significant hepatic derangement } \\
\text { (e.g. bilirubin }>\mathbf{2 x} \text { upper limit of normal, in association with aspartate aminotransferase/ } \\
\text { alanine aminotransferase/ alkaline phosphatase }>3 \times \text { upper limit normal, etc.). "Bleeding" } \\
\text { refers to previous bleeding history and/or predisposition to bleeding, e.g. bleeding diathesis, } \\
\text { anaemia, etc. "Labile INRs" refers to unstable/high INRs or poor time in therapeutic range } \\
\text { (e.g.<60\%). "Drugs/alcohol" use refers to concomitant use of drugs, such as antiplatelet } \\
\text { agents, non-steroidal anti-inflammatory drugs, or alcohol abuse, etc. INR, international } \\
\text { normalized ratio. }\end{array}$} \\
\hline
\end{tabular}

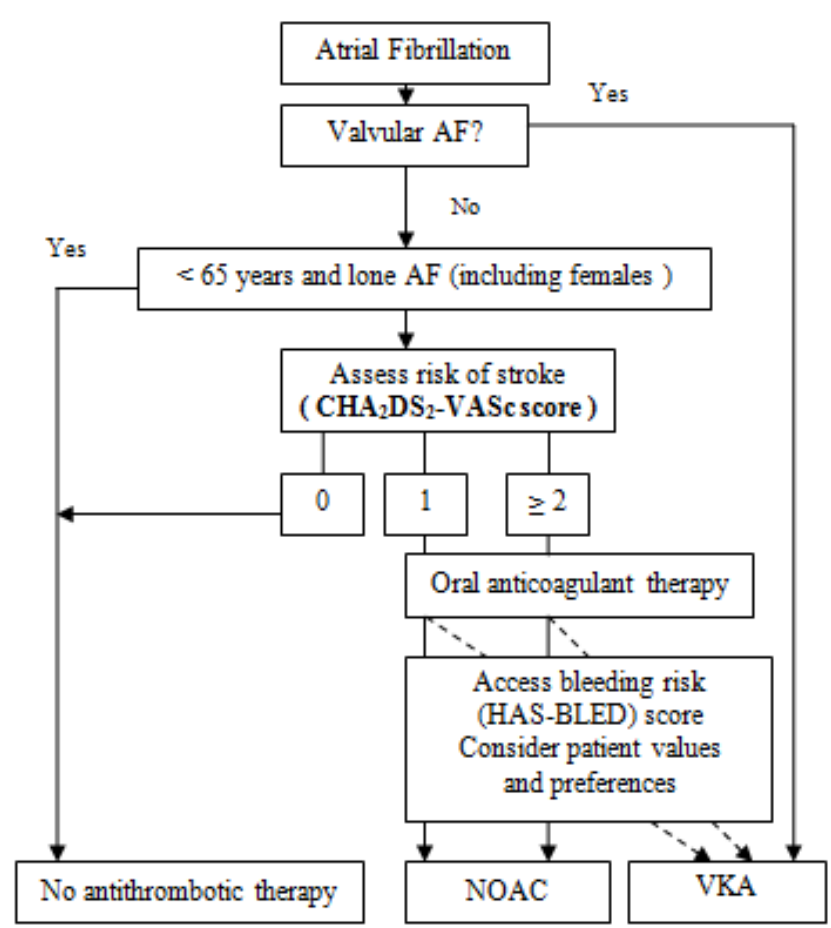

Figure 2. Antithrombotic therapy recommendation by last updated 2012 ESC guideline [20].

Antiplatelet therapy with aspirin plus clopidogrel or less effectively aspirin only, should be considered in patients who refuse any OAC, or cannot tolerate anticoagulants for reasons unrelated to bleeding. Solid line=best option; dashed line= alternative option; CHA2DS2-VASc=see Table 2; HAS-BLED score=see Table 3; Lone $\mathrm{AF}=\mathrm{AF}$ without overt structural heart disease, and defined by a normal clinical history and examination, ECG, chest X-ray and, more recently, the echocardiogram; NOAC, novel oral anticoagulant (dabigatran, rivaroxaban, apixaban); $\mathrm{OAC}$, oral anticoagulant; Valvular $\mathrm{AF}=\mathrm{AF}$ related to rheumatic or 
prosthetic valve diseases; VKA=vitamin $\mathrm{K}$ antagonist (Acenocoumarol, warfarin, phenprocoumon).

Table 4. Recommended level of anticoagulation (INR level) in patients with prosthetic valves in the presence of $\mathrm{AF}[21,22]$.

\begin{tabular}{|c|c|c|}
\hline & $\begin{array}{l}\text { Recommended } \\
\text { levels in } \\
\text { ESC/EACTS } \\
\text { guidelines }\end{array}$ & $\begin{array}{l}\text { Recommended } \\
\text { levels in } \\
\text { ACC/AHA } \\
\text { guidelines }\end{array}$ \\
\hline \multicolumn{3}{|l|}{ Mechanical aortic valve } \\
\hline Low prosthesis Thrombogenicity & 3.0 & $2.5-3.5$ \\
\hline Medium prosthesis & 3.5 & $2.5-3.5$ \\
\hline \multicolumn{3}{|l|}{ Thrombogenicity } \\
\hline High prosthesis Thrombogenicity & 4.0 & $2.5-3.5$ \\
\hline Bioprosthesis aortic valve & $2.0-3.0$ & $2.0-3.0$ \\
\hline \multicolumn{3}{|l|}{ Mechanical mitral valve } \\
\hline Low prosthesis Thrombogenicity & 3.0 & $2.5-3.5$ \\
\hline Medium prosthesis & 3.5 & $2.5-3.5$ \\
\hline \multicolumn{3}{|l|}{ Thrombogenicity } \\
\hline High prosthesis Thrombogenicity & 4.0 & $2.5-3.5$ \\
\hline Bioprosthesis mitral valve & $2.0-3.0$ & $2.0-3.0$ \\
\hline \multicolumn{3}{|c|}{$\begin{array}{l}\text { Prosthesis thrombogenicity: Low=carbomedics, medtronic hall, St Jude } \\
\text { Medical, ON-X; medium=other bileaflet valves; High=Lillehei-Kaster, } \\
\text { Omniscience, Starr-Edwards, Bjork-Shiley and other tilting-disc valves. } \\
\text { ACC; American College of Cardiology, AHA; American Heart } \\
\text { Association, EACTS; European Association for Cardio-Thoracic Surgery, } \\
\text { ESC; European Society of Cardiology. }\end{array}$} \\
\hline
\end{tabular}

Table 5. Intravenous administered pharmacological drugs for ventricular rate control of AF patients in acute setting $[5,6,19,21]$.

\begin{tabular}{|c|c|c|c|c|}
\hline Drug & Loading dose & Onset & Maintenance dose & Side effects \\
\hline \multicolumn{5}{|c|}{ Heart rate control in patients without accessory pathway ${ }^{\mathrm{a}}$} \\
\hline Esmolol & $\begin{array}{l}500 \mathrm{mcg} / \mathrm{kg} \text { over } 1 \\
\mathrm{~min}\end{array}$ & $5 \mathrm{~min}$ & $0.05-0.2 \mathrm{mg} / \mathrm{kg} / \mathrm{min}$ & $\begin{array}{l}\text { Hypotensions, bronchospasm, bradycardia, AV block, heart } \\
\text { failure }\end{array}$ \\
\hline Metoprolol & $\begin{array}{l}2.5-5 \mathrm{mg} / \mathrm{kg} \text { in } 2 \\
\mathrm{~min} \text { to a } \\
\text { maximum of } 3 \\
\text { doses }\end{array}$ & 5 mins & NA & $\begin{array}{l}\text { Hypotension, bronchospasm, bradycardia, AV block, heart } \\
\text { failure }\end{array}$ \\
\hline Propranolol & $0.15 \mathrm{mg} / \mathrm{kg}$ & 5 mins & NA & $\begin{array}{l}\text { Hypotension, bronchospasm, bradycardia, AV block, heart } \\
\text { failure }\end{array}$ \\
\hline Diltiazem $^{\text {b }}$ & $\begin{array}{l}0.25 \mathrm{mg} / \mathrm{kg} \text { over } 2 \\
\min \end{array}$ & $2-7$ mins & 5 to $15 \mathrm{mg} / \mathrm{h}$ & Hypotension, AV block, heart failure, bradicardia \\
\hline Verapamil & $\begin{array}{l}0.75-0.15 \mathrm{mg} / \mathrm{kg} \\
\text { in } 2 \mathrm{~min}\end{array}$ & 3-5 mins & NA & $\begin{array}{l}\text { Hypotension, AV block, heart failure, bradicardia, interaction } \\
\text { with digoxine }\end{array}$ \\
\hline $\operatorname{Digoxin}^{c}$ & $\begin{array}{l}0.50 \mathrm{mg} \text { initially, } \\
\text { then } 0.25 \mathrm{mg} / 6 \mathrm{~h} \\
\text { to } \max 1.5 \mathrm{mg}\end{array}$ & $2 \mathrm{hrs}$ & $0.125-0.25 \mathrm{mg} / \mathrm{day}$ & $\begin{array}{l}\text { AV block, bradycardia, digitalis intoxication (gastrointestinal, } \\
\text { ocular, neurological, proarrhythmia) }\end{array}$ \\
\hline \multicolumn{5}{|c|}{ Heart rate control in patients with accessory } \\
\hline Amiodarone $^{d}$ & $\begin{array}{l}150 \mathrm{mg} \text { over } 10 \\
\text { min (Repeat in } 10- \\
30 \text { min if } \\
\text { necessary) }\end{array}$ & $<30 \min ^{\mathrm{e}}$ & $\begin{array}{l}0.5 \text { to } 1 \mathrm{mg} / \mathrm{min} \text { IV then } \\
200 \mathrm{mg} \text { daily, orally }\end{array}$ & $\begin{array}{l}\text { Hypotension, bradicardia, pulmonary toxicity, hepatotoxicity, } \\
\text { photosensitivity, corneal deposits, skin discoloration, hypo/ } \\
\text { hyperthyroidism, polyneuropathy, optic neuropathy, interaction } \\
\text { with acenocoumarol /warfarin, bradycardia, QT/QTc } \\
\text { prolongation, torsades de pointes (rare). }\end{array}$ \\
\hline \multicolumn{5}{|c|}{$\begin{array}{l}\left.{ }^{\text {a }}\right) \text {. In the presence of preexitation administration of these drugs can cause torsades de pointes while bloking AV node and enhancing } \\
\text { antioventricular conduction over accessory pathway; }\left({ }^{b}\right) \text {.Diltiazem (iv) could be used in acute setting of heart failure for ventricular } \\
\text { control of AF. But routine oral administration of diltiazem/verapamil increases mortality in heart failure patients; }\left({ }^{c}\right) \text {.According to } \\
\text { current guidelines digoxine iv use for heart rate control can be given to heart failure patients. Caution should be taken to give long-time } \\
\text { therapy because a recent analysis of the AFFIRM trial showed an overall } 41 \% \text { increase in all-cause mortality in patients taking digoxin vs } \\
\text { those not taking digoxin. The increase in all-cause mortality was consistently observed in men and women and in patients with and } \\
\text { without underlying heart failure [27]; }\left({ }^{\mathrm{d}}\right) \text {. A caution should be taken for administration of amiodarone in heart failure patients for heart } \\
\text { rate control if duration of AF and effective thromboprophylaxis situation is not known. Because it can cardiovert rhythm to SR. It is } \\
\text { generally recommended for critically ill patients; }\left({ }^{\mathrm{e}}\right) \text {. Onset of effect of amiodarone is }<30 \text { min if administered iv route and } 1-3 \text { weeks for } \\
\text { oral route [28]; AV. atrioventricular; NA. not applicable. }\end{array}$} \\
\hline
\end{tabular}


Table 6. Parameters considered while attempting $\mathrm{CV}$ in patients with AF [7, 8, 19, 20, 29-35].

\begin{tabular}{|c|c|}
\hline Supportive parameters & Unsupportive parameters \\
\hline a) Clinical & a) Clinical \\
\hline First episode of AF & Permanent AF (especially >2 year) \\
\hline History of paroxysmal AF & $\begin{array}{l}\text { Long-standing persistant } \mathrm{AF} / \mathrm{AFL}(>1 \text { year) with history } \\
\text { of failure of antiarrhyhthmic drugs } \pm \text { multiple electrical } \mathrm{CV} \\
\text { for maintaining SR }\end{array}$ \\
\hline $\begin{array}{l}\text { AF secondary to transient or treatable diseases } \\
\text { (hyperthyroidism, intoxication, drugs, pneumonia, etc.) }\end{array}$ & Early relapse $<1$ month after $\mathrm{CV}$ \\
\hline $\begin{array}{l}\text { AF causing severe symptoms (angina pectoris, heart failure, } \\
\text { syncope, exercise intolerance ) despite rate control therapy }\end{array}$ & Antiarrhythmic drugs intolerance/side effects \\
\hline More symptomatic & Less symptomatic \\
\hline Age $<65$ years & Age $\geq 65$ years \\
\hline No HT or HT under control & HT (uncontrolled under multiple drug therapy) \\
\hline No previous antiarrhythmic drug failure & Previous antiarrhythmic drug failure \\
\hline Congestive heart failure clearly exacerbated by AF & No history of congestive heart failure excerbated by AF \\
\hline Patient preference & Patient preference \\
\hline b) Echocardiographic & b) Echocardiographic \\
\hline Left atrial size $<45 \mathrm{~mm}$ & $\begin{array}{l}\text { Severely dilated left atrium }(>55 \mathrm{~m}) \text { iLAV }>33.5 \mathrm{~mL} / \mathrm{m}^{2} \\
{[29-31]}\end{array}$ \\
\hline Right atrial size $<37 \mathrm{~mm}[32]$ & Right atrial size $>37 \mathrm{~mm}$ \\
\hline Preserved LAA peak emptying velocity $[33,34]$. & LAA ejection fraction $<30 \%[35]$ \\
\hline Higher early diastolic strain rate of basal LA [32] & Moderate to severe rheumatic valve diseases \\
\hline
\end{tabular}

Table 7. Recommended dosage and adverse effects of the drugs most commonly used for the restoration of SR [20,37-39].

\begin{tabular}{|c|c|c|c|c|}
\hline Drug & Initial dose & $\begin{array}{l}\text { Maintenance } \\
\text { dose }\end{array}$ & Adverse effects & Contraindication and precautions \\
\hline Amiodarone $^{\mathrm{a}}$ & $\begin{array}{l}5 \mathrm{~g} / \mathrm{kg} \text { i.v. over } 1 \\
\mathrm{~h}\end{array}$ & $5 \mathrm{~g} / \mathrm{h}$ & $\begin{array}{l}\text { Phlebitis, hypotension, bradicardia, } \\
\text { pulmonary toxicity, hepatotoxicity, } \\
\text { photosensitivity, corneal deposits, skin } \\
\text { discoloration, hypo/ hyper -thyroidism, } \\
\text { polyneuropathy, optic neuropathy, } \\
\text { interaction with acenocoumarol /warfarin, } \\
\text { bradycardia, QT/QTc prolongation, } \\
\text { torsades de pointes (rare) }\end{array}$ & $\begin{array}{l}\text { Hypo or hyper thyroidism, QTc } \\
\text { interval >500 msec, when using } \\
\text { concomitant therapy with QT- } \\
\text { prolonging drugs, dose of VKAs and } \\
\text { digitoxin/digoxin should be reduced }\end{array}$ \\
\hline Flecainide $^{b}$ & $\begin{array}{l}2 \mathrm{mg} / \mathrm{kg} \text { i.v. over } \\
10 \mathrm{~min} \text {, Or } 200- \\
300 \mathrm{mg} \text { p.o. }(\text { pill } \\
\text { in the pocket) }\end{array}$ & $100-150 \mathrm{mg} / 12 \mathrm{~h}$ & $\begin{array}{l}\text { Decrease in BP, may prolong QRS } \\
\text { duration and hence the QT Interval, may } \\
\text { inadvertently increase the ventricular rate } \\
\text { due to CV to AFL and } 1: 1 \text { conduction to } \\
\text { the ventricles }\end{array}$ & $\begin{array}{l}\text { Not suitable for patients with marked } \\
\text { structural heart disease, branch block } \\
\text { or wide QRS complex, postinfarction } \\
\text { scar, heart failure. }\end{array}$ \\
\hline Ibutilide & $\begin{array}{l}1 \mathrm{mg} \text { i.v. over } 10 \\
\min \end{array}$ & $\begin{array}{l}1 \mathrm{mg} \text { i.v. over } 10 \\
\text { min after waiting } \\
\text { for } 10 \mathrm{~min} \text { (if } \mathrm{AF} \\
\text { persists) }\end{array}$ & $\begin{array}{l}\text { Can cause prolongation of the QT interval } \\
\text { and torsades de pointes, watch for } \\
\text { abnormal T-U waves or QT prolongation, } \\
\text { Will slow the ventricular rate, AV block }\end{array}$ & $\begin{array}{l}\text { LV hypertrophy }(\mathrm{WT} \geq 1.4 \mathrm{~cm}) \text {, severe } \\
\text { LV systolic dysfunction }(\mathrm{EF}<\% 20) \text {, } \\
\text { ACS, concurrent use of class IA or III } \\
\text { antiarrhythmics within } 4 \text { hours after } \\
\text { ibutilide, QTc interval }>440 \mathrm{msec}\end{array}$ \\
\hline Propafenone $b$ & $\begin{array}{l}2 \mathrm{mg} / \mathrm{kg} \text { i.v. over } \\
10 \mathrm{~min} \text { or } 450- \\
600 \mathrm{mg} \text { (oral) } \\
\text { (pill in the } \\
\text { pocket) c }\end{array}$ & $\begin{array}{l}150-300 \mathrm{mg} / 8 \mathrm{~h} \\
\text { p.o. }\end{array}$ & $\begin{array}{l}\text { rate, but may inadvertently increase the } \\
\text { ventricular rate due to CV to AFL and } 1: 1 \\
\text { conduction to the ventricles }\end{array}$ & $\begin{array}{l}\text { heart failure and LV hypertrophy } \\
\text { (WT } \geq 1.4 \mathrm{~cm} \text { ), caution in the presence } \\
\text { of conduction system disease (branch } \\
\text { block or wide QRS complex) and } \\
\text { renal impairment }\end{array}$ \\
\hline Vernakalant & $\begin{array}{l}3 \mathrm{mg} / \mathrm{kg} \text { i.v. over } \\
10 \mathrm{~min}\end{array}$ & $\begin{array}{l}\text { Second infusion } \\
\text { of } 2 \mathrm{mg} / \mathrm{kg} \text { i.v. } \\
\text { over } 10 \text { min after } \\
15 \text { min first } \\
\text { infusion (if } \mathrm{AF} \\
\text { persists) }\end{array}$ & $\begin{array}{l}\text { Sneezing, dysgeusia, paraesthesia, nausea, } \\
\text { cough, pruritus, dizziness, hyperhidrosis, } \\
\text { hypotension or decrease in BP } 39\end{array}$ & $\begin{array}{l}\text { Contraindicated in moderate or severe } \\
\mathrm{HF} \text {, severe AS, ACS (in the last } 30 \\
\text { days) and hypotension } \\
(\mathrm{SBP}<100 \mathrm{mmHg}) \text { caution in mild HF }\end{array}$ \\
\hline \multicolumn{5}{|c|}{$\begin{array}{l}\left({ }^{a}\right) \text {. Amiodarone administration dose scheme in Table } 6 \text { can be used for the restoration of SR; }\left({ }^{b}\right) \text {. Flecainide and propafenone can } \\
\text { increase QRS duration. An increase }>\% 25 \text { from baseline indicates discontiuation or dose reduction of these drugs; }\left({ }^{c}\right) \text {. Pill-in-the- } \\
\text { pocket' technique-preliminary assessment in a medically safe environment and then used by the patient in the ambulatory setting. } \\
\text { ACS. Acute coronary syndromes; AF. Atrial fibrillation; AFL. Atrial flutter; AS. Aortic stenosis; BP. Blood pressure; CV. } \\
\text { Cardioversion; EF. Ejection fraction; HF. Heart failure; LV. Left ventricular; SBP. Systolic blood pressure; VKAs. Vitamine K } \\
\text { antagonists; WT. Wall thickness. }\end{array}$} \\
\hline
\end{tabular}




\section{Management of recent-onset AF/AFL in the ED}

Initial management; in all patients presenting to the emergency department with acute $\mathrm{AF}$, immediate provision of supplementary oxygen, establishment of an intravenous line, continuous electrocardiographic monitoring, blood pressure and 12 lead ECG is mandatory. In the emergency department assessment of AF (Table 8): Its duration, classification, onset date, date of discovery of AF, frequency, precipitating factors and symptoms should be determined. Special attention should also be paid to the diseases in etiology and also investigate ECG for the signs of left ventricular hypertrophy, preexcitation, bundle branch block, prior myocardial infraction and measure QRS and QT/Qtc interval, and investigate chest $\mathrm{X}$ ray for the signs of pulmonary diseases and structural heart diseases [40, 41].

The principles of emergency management of AF are haemodynamic stabilization, prevention of thromboembolism and symptom relief. These goals are achieved by a three part approach to management: thromboprophylaxis, acute rate control and acute rhythm control or $\mathrm{CV}$ of $\mathrm{AF}$ to $\mathrm{SR}$. CV of AF to SR can be obtained by scheduled emergent electrical CV or emergent/urgent medical (pharmacological) $\mathrm{CV}$ by antiarrhythmic drugs and facilitated or pharmacological enhanced (medical plus) electrical CV.

Table 8. Initial assessment and management of AF/AFL in ED [40-46].

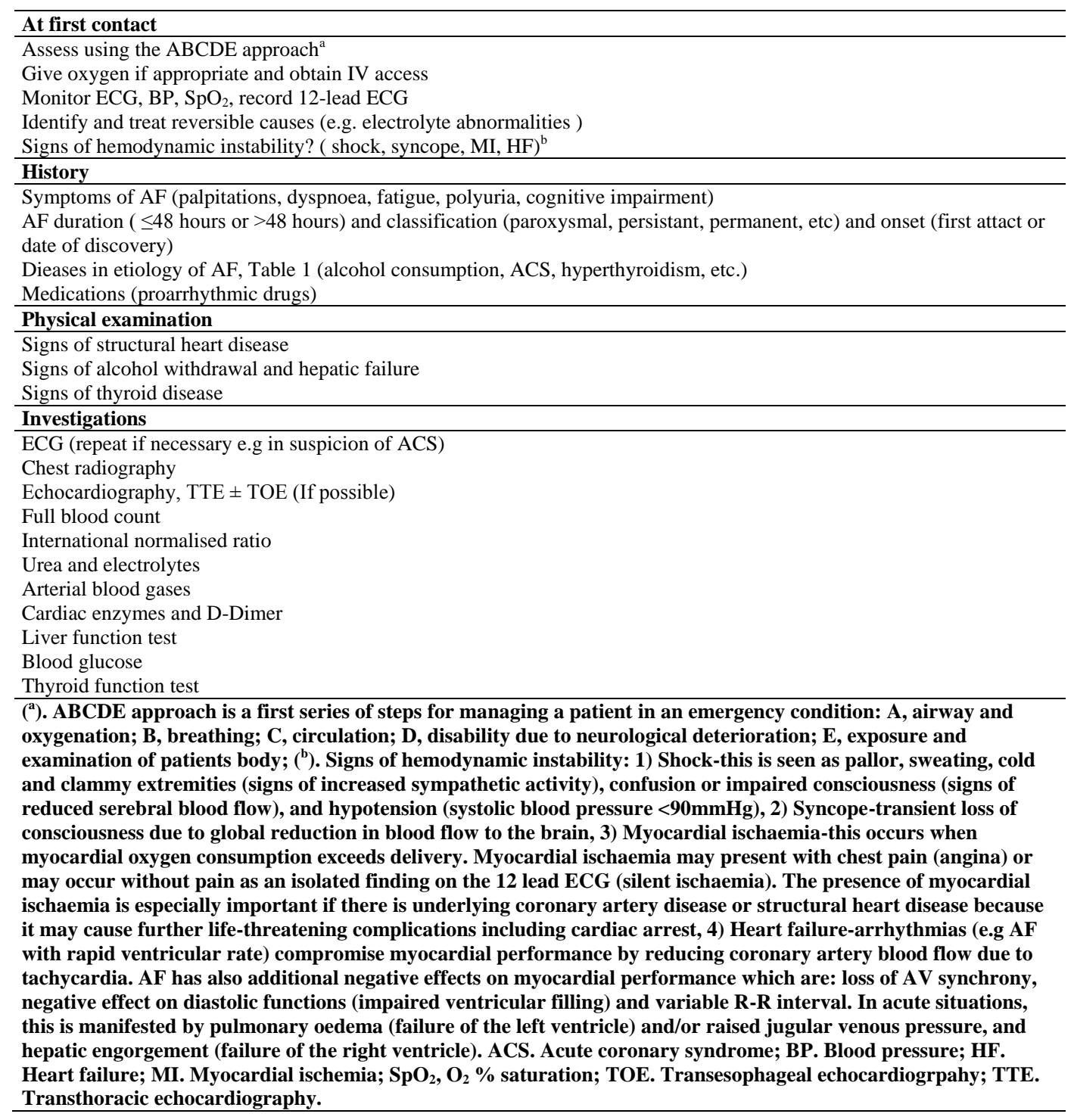




\section{Treatment of acute precipitants or reversible underlying dieases and distrubances}

In some cases the AF has been clearly triggered by another condition, most commonly respiratory tract infection or other sepsis, general anaesthesia, acute pericarditis or myocardial infarction/ischaemia. Sometimes the precipitant (e.g. pneumonia) may require treatment in its own right and if possible CV should be deferred until after it has resolved to reduce the risk of recurrent AF [5-8]. So, before initiating antiarrhythmic drug therapy, treatment of precipitating or reversible causes of AF (Table 1) is recommended [47].

\section{Cardioversion of AF/AFL in ED}

$\mathrm{CV}$ may be achieved by means of drugs or electrical shocks. Drugs were commonly used before electrical CV became a standard procedure [5]. The clinical presentation of acute AF depends on a number of factors, particularly ventricular rate, loss of AV synchrony, cycle length irregularity, and the presence of underlying cardiac disease. The resulting spectrum of symptomatology is broad. Some patients are completely asymptomatic. More often they complain of palpitation, dyspnoea, or weakness, possibly associated with chest discomfort or lightheadedness, but the attack is still reasonably well tolerated. In a minority of cases AF is poorly tolerated due to severe angina or hemodynamic decompensation, i.e. pulmonary oedema, hypotension or circulatory collapse with syncope (rarely). It would be unusual for acute AF to cause significant hemodynamic instability in the absence of structural heart disease, particularly impaired LV function and/or abnormal compliance (e.g. left ventricular hypertrophy, acute myocardial infarction, etc.), or valvular problems such as mitral stenosis or aortic stenosis. Immediate electrical CV should be considered AF causing hemodynamically instability without considering its duration and classification, supportive clinical or echocardiographic parameters, antiarrhythmic drugs and also patient's anticoagulation status (Figure 3) [6, 20]. But, in the meanwhile thromboprophylaxis should be initiated. Immediate electrical $\mathrm{CV}$ is also recommended for $\mathrm{AF}$ involving preexitation when antegrade conduction via accessory pathway is very fast (Figure 4). Because this situtation carries very high risk of rapid progression to ventricular tachycardia/fibrillation and abrupt hemodynamic compromise [44].

Patients presenting within 48 hours of the onset of AF can be offered immediate pharmacological or electrical CV with heparin (LMWH or unfractionated heparin) (Figure 3). CV of AF more than 48 hours after onset is associated with 5-7\% risk of embolic events. Anticoagulation for 3-4 weeks prior to CV will reduce this risk to 0$1.6 \%$. The risk of thromboembolism is due to both pre-CV left atrial thrombus and "atrial stunning" following restoration of SR. Early electrical or pharmacological CV may be performed if TOE has excluded left atrial thrombus but must be followed by full anticoagulation for 4 weeks to prevent de novo thrombus formation due to atrial stunning. If TOE showed the presence of thrombus in left atrial or left atrial appendage, rate control strategy should be chosen with therapeutic oral anticoagulation for 3 weeks. If trombus resolution is seen at TOE after 3 weeks, CV should be performed. But in the case of thrombus persistance at TOE, treatment should be long term oral anticoagulation and rate control $[6,20]$. 


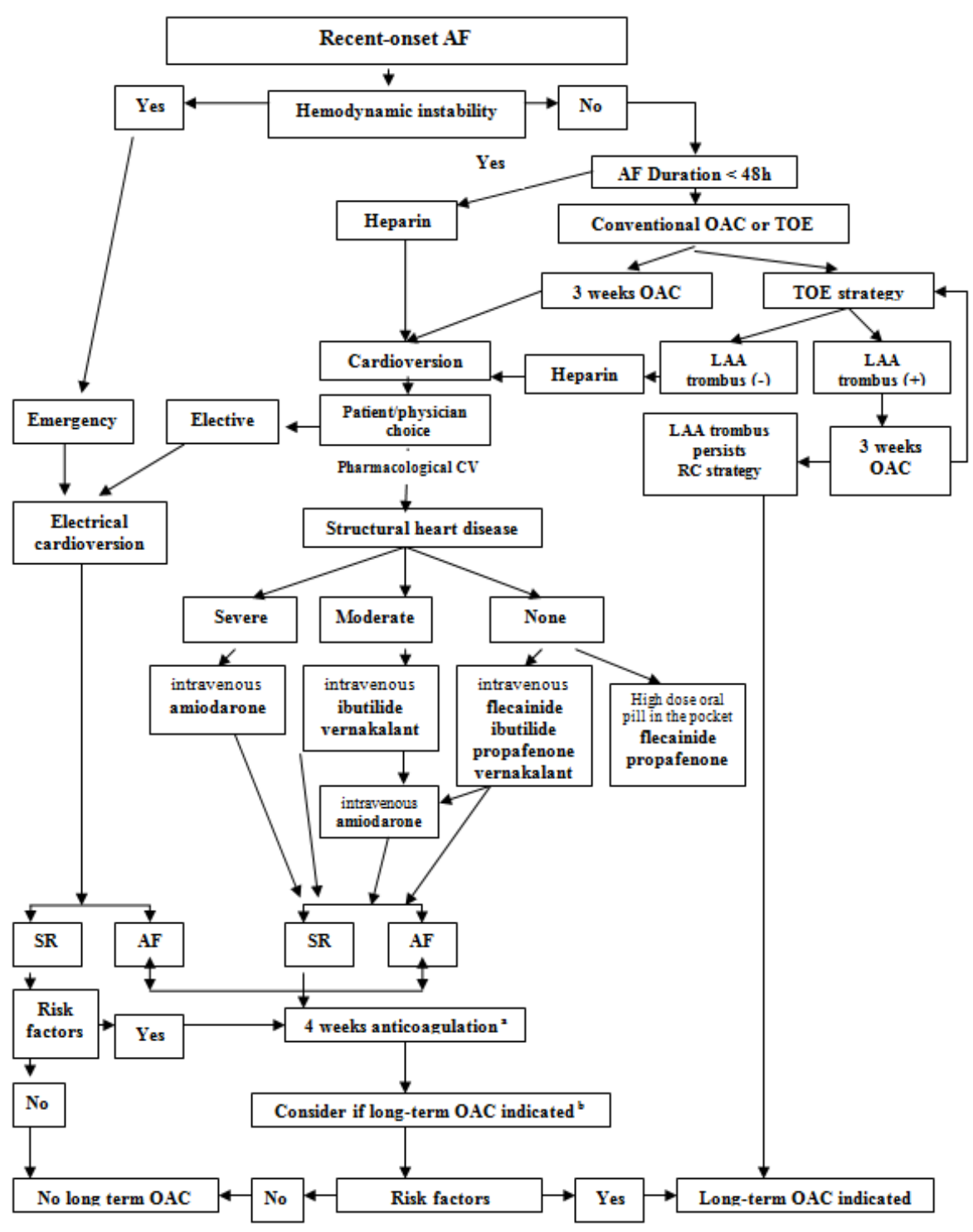

Figure 3. Indications for electrical and pharmacological CV, and choice of antiarrhythmic drugs for pharmacological $\mathrm{CV}$ in patients with recent-onset $\mathrm{AF}$ [6, 20]; a. Anticoagulation should normally be continued for 4 weeks after a $C V$ attempt except when AF is recent onset and no risk factors are present; $b$. Long-term $\mathrm{OAC}$ if there is stroke risk factors and/or risk of $\mathrm{AF}$ recurrence/presence of thrombus. AF; atrial fibrillation. CV; cardioversion. LAA; left atrial appendage. OAC; oral anticoagulant. RC; rate control. SR; sinus rhythm. TOE; transoesophageal echocardiography.

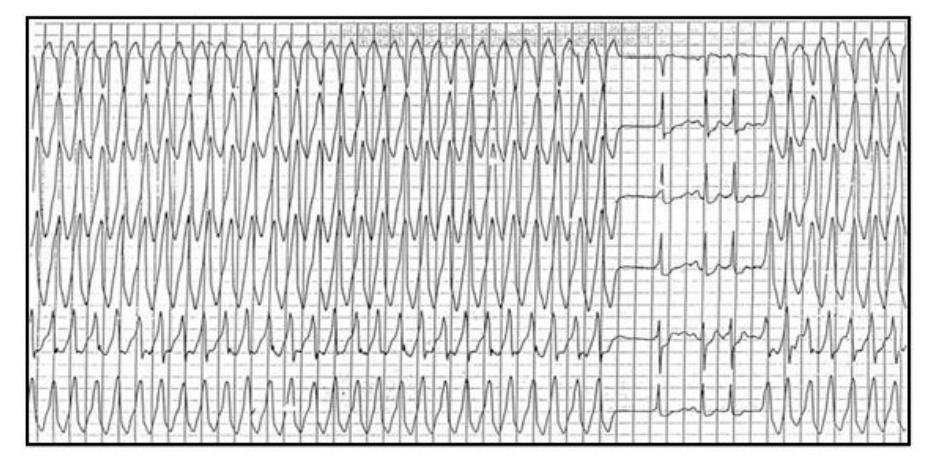

Figure 4. AF with preexitation syndrome. Antegrade conduction is via accessory pathway during wide QRS complex tachycardia. Antegrade conduction is through AV node for a very short period which helps better understanding of underlying arrhythmia. 


\section{Electrical cardioversion of AF/AFL in ED}

Electrical CV or direct-current CV involves delivery of an electrical shock synchronized with the intrinsic activity of the heart by sensing the R wave of the ECG to ensure that electrical stimulation does not occur during the vulnerable phase of the cardiac cycle. Electrical CV is used to normalize all abnormal cardiac rhythms except ventricular fibrillation. The term defibrillation implies an asynchronous discharge, which is appropriate for correction of ventricular fibrillation because R-wave synchronization is not feasible, but not for AF [5].

Electrical CV success rates vary from 75 to $93 \%$. They are inversely related to the AF duration, chest wall impedance, and left atrial size [48-52]. Indeed, success rates vary according to the point in time that success is defined. In one series of 1.838 eletrical CV, success rates, when the duration of $\mathrm{AF}$ was $<30,30$ to 90,90 to 180 , and $>180$ days was 84, 78, 77, and 66 percent, respectively.53 When AF has been present for more than five years, success rates are only approximately 50 percent [50]. Indications and contraindications of AF/AFL is given in Table $9[5,6,54,55]$.

\section{Technique}

Electrical CV should be performed with the patient in a fasting state under adequate sedation for elective cases. Drugs chosen for sedation should have short acting effect which produce conscious sedation and also least effect on cardiovascular system while allowing rapid recovery. Oxygen saturation and electrolytes should be normal and anticoagulation status monitored. Continous $\mathrm{O}_{2}$ flow via nasal cannulea or mask should be given before and after electrical $\mathrm{CV}$, duration of $\mathrm{O}_{2}$ therapy belongs to patient saturation status. But, $\mathrm{O}_{2}$ flow must be stopped or removed at least from $1 \mathrm{~m}$ from the patient's chest during CV to prevent fire [5, 42, 43, 46]. External pacing pads may be used for both $\mathrm{CV}$ and for prophylaxis of asystole or bradycardia if ensue after electrical $\mathrm{CV}$ or if sick sinus syndrome is suspected [56].

Success of electrical CV depends on adequacy of delivered current flow through the heart. The major determinants of adequacy of delivered current are: The nature of the shock waveform (mono or biphasic), level of delivered energy. In terms of shock waveform, both monophasic and biphasic waveforms are used [42, 43, 46]. Currently, most evidence favors the use of biphasic external defibrillators due to their categorically lower energy requirements and greater efficacy [57]. Furthermore, fewer shocks are required, thereby potentially reducing procedure times and thus, requirements for intravenous sedation. A lower incidence of skin burns and less skeletal muscle damage have also been reported. Additionally biphasic waveforms result in fewer post-shock arrhythmias, and a shorter period of myocardial stunning [58]. Currently, two conventional positions (anterolateral and anteroposterior) are commonly used for electrode placement. Several studies have shown that anteroposterior electrode placement is more effective than anterolateral placement. If initial shocks are unsuccessful for terminating the arrhythmia, theelectrodes should be repositioned and CV repeated [6].

In the presence of pacemaker or implantable cardioverter defibrillator, the electrode paddle should be at least $8 \mathrm{~cm}$ from the pacemaker battery, and the anteroposterior paddle positioning is recommended. Biphasic shocks are preferred because they require less energy for AF termination. In pacemaker-dependent patients, an increase in pacing threshold should be anticipated. These patients should be monitored carefully. After CV, the device should be interrogated and evaluated to ensure normal function [6].

The amount of energy needed for initial attempts of electrical CV has been controversial. Once satisfactory synchronisation is obtained, sedation or anaesthesia is initiated, and a shock is delivered. After shock delivery, if CV is unsuccessful, CV with higher energy is attempted. This can be repeated until the arrhythmia terminates or the decision is made to abandon electrical CV. Initial energy requirements are usually $\geq 200$ joules for monophasic waveform and $\geq 100$ joules for biphasic waveform, with possibly more being required in obese patients and long-standing AF. The initial energy may be lower for CV 
of AFl, usually the initial energy level for successful CV is 50 joules with a biphasic defibrillator and 50-100 joules with a monophasic defibrillator [5, 6]. But, in the hemodynamic instability condition, electical CV should be performed with maximal energy of the present defibrillator [42, 43, 46].

\section{Complications}

The risks and complications of electrical $\mathrm{CV}$ are associated primarily with thromboembolic events, post-CV arrhythmias, and the risks of general anaesthesia. Thromboembolic events have been reported in about 3\% to $5 \%$ of patients who did not receive anticoagulation before $\mathrm{CV}$, whereas it is only $0 \%$ to $1 \%$ by adequate anticoagulation or by exclusion of left atrium thrombi before the procedure [59, 60]. Skin burns are a common complication. In patients with sinus node dysfunction, especially in elderly patients with structural heart disease, prolonged sinus arrest without an adequate escape rhythm may occur. Dangerous arrhythmias, such as ventricular tachycardia and fibrillation, may arise in the presence of hypokalaemia, digitalis intoxication, or improper synchronization ( $\mathrm{R}$ on $\mathrm{T}$ phenomenone). The patient may become hypoxic or hypoventilate from sedation, but hypotension and and pulmonary oedema are rare $[5,6]$. But, over-the-night stay is generally recommended.

Table 9. Indications and contraindications of electrical CV of recent-onset AF/AFL in ED.

\begin{tabular}{|c|c|}
\hline Indications & \\
\hline 1. Emergent electrical CV & $\begin{array}{l}\text { For patients with recent-onset AF and rapid ventricular rate who has hemodynamic } \\
\text { instability (ongoing myocardial ischemia, symptomatic hypotension, heart failure) that } \\
\text { does not respond promptly to pharmacological drugs. }\end{array}$ \\
\hline Emergent electrical CV & $\begin{array}{l}\text { For patients with recent-onset AF involving preexcitation when very rapid tachycardia or } \\
\text { hemodynamic instability occurs. }\end{array}$ \\
\hline Urgent electrical CV & $\begin{array}{l}\text { For patients without hemodynamic instability when symptoms of } \mathrm{AF} \text { are unacceptable to } \\
\text { the patient. In case of early relapse of AF after } \mathrm{CV} \text {, repeated electrical } \mathrm{CV} \text { may be made } \\
\text { following administration of antiarrhythmic medication. }\end{array}$ \\
\hline Elective electrical CV & $\begin{array}{l}\text { As an initial treatment may be considered in order to initiate a long-term rhythm control } \\
\text { management strategy for patients with recent-onset AF within } 48 \mathrm{~h} \text { of onset by } \\
\text { patient/physcian choice. }\end{array}$ \\
\hline Elective electrical CV & $\begin{array}{l}\text { As an initial treatment may be considered in order to initiate a long-term rhythm control } \\
\text { management strategy for patients with recent-onset AF over } 48 \mathrm{~h} \text { of onset when TOE has } \\
\text { excluded LAA thrombus by patient/physcian choice. }\end{array}$ \\
\hline $\begin{array}{l}\text { Enhanced / facilitated elective } \\
\text { electrical CV }\end{array}$ & $\begin{array}{l}\text { Which is electrical CV after pretreatment with antiarrhythmic drugs (amiodarone, } \\
\text { flecainide, propafenone or ibutilide) in order to enhance success of electrical CV and } \\
\text { prevent recurrent AF, should be considered for patients with recent-onset AF within } 48 \mathrm{~h} \\
\text { of onset or over } 48 \mathrm{~h} \text { if thrombus exluded at TOE. }\end{array}$ \\
\hline Electice electrical CV & $\begin{array}{l}\text { Should be considered in order to to initiate a long-term rhythm control management } \\
\text { strategy after antiarrhythmic drug failure to restore SR in patients with recent-onset AF } \\
\text { within } 48 \mathrm{~h} \text { of onset or over } 48 \mathrm{~h} \text { if thrombus exluded at TOE. }\end{array}$ \\
\hline \multicolumn{2}{|l|}{ Contraindications } \\
\hline $\begin{array}{l}\text { Known atrial thrombus and no } \\
\text { In the presence of digitalis toxi } \\
\text { Severe electrolyte imbalance }(\mathrm{e} \\
\text { Frequent repetition of direct-cu } \\
\text { relapses of AF after multiple C } \\
\text { In the presence of doubt about } \\
\text { [43-45]. } \\
\text { Elective electrical CV without } \\
\text { Elective electrical CV in patien }\end{array}$ & $\begin{array}{l}\text { nergent indication for CV. } \\
\text { ty. } \\
\text { hypokalemia) or hyperthyroidsm and no emergent indication for CV. } \\
\text { ent } \mathrm{CV} \text { is not recommended for patients who have relatively short periods of SR between } \\
\text { procedures despite prophylactic antiarrhythmic drug therapy. } \\
\text { derlying rhythm (e.g multifocal atrial tachycardia) and no emergent indication for CV } \\
\text { lequate anticoagulation. } \\
\text { who can not be safely sedated. }\end{array}$ \\
\hline
\end{tabular}

\section{Pharmacological cardioversion of AF/AFL in ED}

Pharmacological CV should be considered to hemodynamically stable patients (Table 10). The conversion rate with antiarrhythmic drugs is lower than with electrical $\mathrm{CV}$, but does not require conscious sedation or anaesthesia, and may facilitate the choice of antiarrhythmic drug therapy to prevent recurrent AF. Most patients who undergo pharmacological CV require continuous medical supervision and ECG monitoring during the drug infusion and for a period afterwards (usually about half the drug elimination half-life) to detect proarrhythmic events such as ventricular proarrhythmia, sinus node arrest, or atrioventricular block. Several agents are available for pharmacological CV (Table 7) [5, 6]. Antiarrhythmic drug choice is based on patients characteristics; presence 
or absence of structural heart disease and antiarrhythmic drug features; side effects, success rates, contraindications (Table 7, Table 11, Figure 3).

Table 10. Indications and contraindications of pharmacological $\mathrm{CV}$ of recent-onset AF/AFL in ED.

\begin{tabular}{|c|c|}
\hline \multicolumn{2}{|l|}{ Indications } \\
\hline Pharmacological CV & $\begin{array}{l}\text { as an initial treatment may be considered in order to initiate a long-term rhythm control } \\
\text { management strategy for patients with recent-onset AF within } 48 \mathrm{~h} \text { of onset by } \\
\text { patient/physcian choice. }\end{array}$ \\
\hline Pharmacological CV & $\begin{array}{l}\text { as an initial treatment may be considered in order to initiate a long-term rhythm control } \\
\text { management strategy for patients with recent-onset AF over } 48 \mathrm{~h} \text { of onset when TOE has } \\
\text { excluded LAA thrombus by patient/physcian choice. }\end{array}$ \\
\hline Pharmacological CV & $\begin{array}{l}\text { should be considered in order to to initiate a long-term rhythm control management strategy } \\
\text { after electrical CV failure to restore SR in patients with recent-onset AF within } 48 \mathrm{~h} \text { of onset } \\
\text { or over } 48 \mathrm{~h} \text { if thrombus exluded at TOE }\end{array}$ \\
\hline \multicolumn{2}{|c|}{$\begin{array}{l}\text { Pretreatment with antiarrhythmic drugs (amiodarone, flecainide, propafenone or ibutilide) in order to enhance success of } \\
\text { electrical CV (enhanced / facilitated elective electrical CV) and prevent recurrent AF, in patients patients with recent-onset } \\
\text { AF within } 48 \mathrm{~h} \text { of onset or over } 48 \mathrm{~h} \text { if thrombus exluded at TOE. }\end{array}$} \\
\hline \multicolumn{2}{|c|}{ Contraindications $^{\mathrm{a}}$} \\
\hline $\begin{array}{l}\text { Known atrial thrombi } \\
\text { Severe electrolyte im } \\
\text { Pharmacological CV }\end{array}$ & $\begin{array}{l}\text { (e.g. hypokalemia) or hyperthyroidism } \\
\text { adequate anticoagulation }\end{array}$ \\
\hline (a). Antiarrhythmic & ecific contraindications and cautions are described in Table 7 . These contraindications \\
\hline
\end{tabular}

Amiodarone is a class III antiarrhythmic drug. Results of many clinical trials showed that the efficacy of amiodarone ranged from $34 \%$ to $69 \%$ with bolus ( 3 to $7 \mathrm{mg} / \mathrm{kg}$ body weight) regimens and $55 \%$ to $95 \%$ when the bolus was followed by a continuous infusion (900 to $3000 \mathrm{mg}$ for the first 24h). Predictors of successful conversion were shorter duration of AF, smaller LA size, and higher amiodarone dose. Amiodarone was not superior to other antiarrhythmic drugs for conversion of recent-onset AF but was relatively safe in patients with structural heart disease, including those with LV dysfunction and coronary artery disease for whom administration of class IC drugs (flecainide, propafenone) is contraindicated [5, 6]. Class IC drugs were more effective than amiodarone in converting AF when analyzed for the first $2 \mathrm{hr}$ after start of therapy, for the first 3 to $5 \mathrm{hr}$, and for the first 6 to $8 \mathrm{hr}$ (66\% SR in the amiodarone group vs. $71 \%$ in the class IC group). At 24hr, however, no significant difference persisted between the various drugs [61]. Particularly if one aims at rapid restoration of SR, amiodarone appears to be less effective than class IC drugs for the pharmacological CV of AF. The complex pharmacokinetic and pharmacodynamic profile of amiodarone seems to be responsible for its somewhat delayed onset of action [5, 6, 61].

Flecainide administered orally or intravenously was effective for $\mathrm{CV}$ of recent-onset $\mathrm{AF}$ in placebo-controlled trials. The success of a single oral loading dose $(300 \mathrm{mg})$ for CV of recent-onset $\mathrm{AF}$ ranged from $57 \%$ to $68 \%$ at 2 to $4 \mathrm{~h}$ and $75 \%$ to $91 \%$ at $8 \mathrm{~h}$ after drug administration. Single oral loading and intravenous loading regimens of flecainide were equally efficacious, but a response usually occurs within $3 \mathrm{~h}$ after oral administration and $1 \mathrm{~h}$ after intravenous administration. Arrhythmias, including AFl with rapid ventricular rates and bradycardia after conversion, are relatively frequent adverse effects [5, 6, 62].

Propafenone is an effective antiarrhyhthmic drug in converting recent-onset AF to SR. Within a few hours of intravenous administration, the expected conversion rate was between 41 and $91 \%$. The corresponding early conversion rates in placebo treated patients were 10-29\%. Propafenone has only a limited efficacy for conversion of persistent AF and for AFl. Similar to flecainide, propafenone should be avoided in patients with underlying heart disease involving abnormal LV function and ischaemia. In addition, owing to its weak b-blocking properties, propafenone should be avoided in severe obstructive lung disease. The time to conversion varies from $30 \mathrm{~min}$ to $2 \mathrm{~h}$. Propafenone is also effective if administered orally (conversion between 2 and $6 \mathrm{~h}$ ). Because of proarrhythmia risk, both flecainide and propafenone is contraindicated in marked left ventricular hypertrophy (wall thickness $\geq 1.4 \mathrm{~cm}$ ) $[5,6,62]$. 
Ibutilide is an class III antiarrhythmic drug. Efficacy of conversion rates within $90 \mathrm{~min}$ is about $50 \%$ in several well-designed randomized studies, placebo controlled or with a control group of drugs with known little effect. The time to conversion is $30 \mathrm{~min}$. The most important side effect is polymorphic ventricular tachycardia, most often nonsustained, but electrical CV may be needed, and the QTc interval is expected to increase by $60 \mathrm{~ms}$. Ibutilide is, however, more effective for conversion of AFl than AF [5, 6, 38].

Table 11. Comparison of the conversion success rates of ibutilide, amiodarone, propafenone, dofetilide, and flecainide in recent-onset AF, persistent AF, and recent-onset AFL [38].

\begin{tabular}{llll}
\hline $\begin{array}{l}\text { Pharmacological } \\
\text { agent }\end{array}$ & Conversion success rates (\%) & & \\
\cline { 2 - 4 } & Recent-onset AF & Persistent AF & Conversion success rates (\%) \\
\hline Ibutilide & Ibutilide & $31-77$ & 48 \\
Amiodarone & $\begin{array}{l}34-69 \text { (with bolus regimen) 55-95 (with bolus } \\
\text { followed by continuous infusion) }\end{array}$ & 29 \\
Propafenone & $56-87.5$ & $37.5-40$ & 40 \\
Flecainide & $57-68$ (at 2-4hr) 75-91 (at 8hr) & & 13 (with i.v) \\
\hline
\end{tabular}

Vernakalant is a novel agent, which acts preferentially in the atria by blocking several ion channels, resulting in prolongation of atrial refractoriness and rate-dependent slowing of atrial conduction, but has little impact on currents involved in ventricular repolarization $[21,39]$. Vernakalant is not classified in Vaughan-Williams class. Vernakalant has a rapid onset of action and a mean elimination half-life of 3-5 hours. The most common side effects of vernakalant were taste alterations (30\%), sneezing (16\%), paraesthesiae (10\%), and nausea (9\%), which usually resolved within 5-15 minutes. Serious adverse events were reported at similar rates for vernakalant and placebo (4.1\% vs. 3.9\%). Transient hypotension occurred in about 5-7\% of patients treated with vernakalant, the blood pressure returned to baseline within 15-20 minutes after cessation. Hypotension within the first 2 hours was most common in patients with heart failure $(16.1 \%)$, leading to discontinuation of treatment in $2.9 \%$. Vernakalant is effective in CV of patients with $\mathrm{AF} \leq 7$ days or $\mathrm{AF} \leq 3$ days after cardiac surgery and provides a rapid antiarrhythmic effect of converting approximately $50 \%$ of patients within 90 minutes after the start of treatment and a median time to conversion of 8-14 minutes. Vernakalant is administered as a 10minute infusion of $3 \mathrm{mg} / \mathrm{kg}$ and, if AF persists after 15 minutes, a second infusion of $2 \mathrm{mg} / \mathrm{kg}$ can be given [20,39].

Vernakalant has a satisfactory safety profile in patients with mild-to-moderate heart disease, including ischaemic heart disease, but should be used with caution in hemodynamically stable patients with NYHA class I and II heart failure, because of increased risk of hypotension and non-sustained ventricular arrhythmias in these patients. Vernakalant is contraindicated in patients with hypotension (systolic blood pressure $<100$ $\mathrm{mmHg}$ ), recent acute coronary syndromes (within 30 days), NYHA class III and IV heart failure, severe aortic stenosis, and QT interval prolongation (uncorrected QT. 440ms). In direct comparison, vernakalant was significantly superior to intravenous amiodarone in restoration of SR within $90 \mathrm{~min}(51.7 \%$ vs. $5.2 \%$; $\mathrm{P}<0.0001)$ and within 4 hours after infusion $(54.4 \%$ vs. $22.6 \%$; $\mathrm{P}<0.0001)$. Meta-analysis of the efficacy of vernakalant showed that patients were 8.4 times more likely to convert to SR within 90 minutes after vernakalant infusion, than on placebo or amiodarone (95\%CI 4.4-16.3), without excess risk of serious adverse events (risk ratio 0.91; 95\% CI 0.6-1.36) [21, 39]. Clinical trials accessing efficacy of vernakalant are summerized in Table 12 [39]. 
Table 12. Clinical trials assessing efficacy of vernakalant.

\begin{tabular}{|c|c|c|c|c|c|c|c|}
\hline Clinical trial & Type of trial & $\mathbf{N}$ & $\begin{array}{l}\text { Clinical } \\
\text { setting }\end{array}$ & Control group & Primary endpoint & $\begin{array}{l}\text { Vernakalant (i.v) vs } \\
\text { control (p-Value) }\end{array}$ & $\begin{array}{l}\text { Median } \\
\text { time to } \\
\text { CV (min) }\end{array}$ \\
\hline CRAFT63 & RCT/Phase II & 56 & $\begin{array}{l}\mathrm{AF} \\
\text { duration 3- } \\
72 \mathrm{~h}\end{array}$ & Plasebo & $\begin{array}{l}\text { AF termination } \\
\text { within } 30 \mathrm{~min}\end{array}$ & $\begin{array}{l}56 \% \text { vs. } 5 \% \\
(p<0.001)\end{array}$ & 14 \\
\hline ACT I64 & RCT/Phase III & 220 & $\begin{array}{l}\text { AF } \\
\text { duration } \\
3 \mathrm{~h}-7 \mathrm{~d}\end{array}$ & Placebo & $\begin{array}{l}\text { AF termination } \\
\text { within } 90 \mathrm{~min}\end{array}$ & $\begin{array}{l}51.7 \% \text { vs. } 4 \% \\
(\mathrm{p}<0.001)\end{array}$ & 11 \\
\hline ACT II65 & RCT/Phase III & 150 & $\begin{array}{l}\text { AF } \\
\text { postcardiac } \\
\text { surgery }\end{array}$ & Placebo & $\begin{array}{l}\text { AF termination } \\
\text { within } 90 \mathrm{~min}\end{array}$ & $\begin{array}{l}47 \% \text { vs. } 14 \% \\
(p<0.001)\end{array}$ & 12,4 \\
\hline ACT III66 & RCT/Phase III & 265 & $\begin{array}{l}\text { AF } \\
\text { duration } \\
3 \mathrm{~h}-7 \mathrm{~d}\end{array}$ & Placebo & $\begin{array}{l}\text { AF termination } \\
\text { within } 90 \mathrm{~min}\end{array}$ & $\begin{array}{l}51.2 \% \text { vs. } 3.6 \% \\
(p<0.0001)\end{array}$ & 8 \\
\hline ACT IV67 & Open label & 167 & $\begin{array}{l}\text { AF } \\
\text { duration } \\
3 h-7 d\end{array}$ & - & $\begin{array}{l}\text { AF termination } \\
\text { within } 90 \mathrm{~min}\end{array}$ & Vernakalant: $50.9 \%$ & 14 \\
\hline AVRO68 & $\mathrm{RCT}$ & 232 & $\begin{array}{l}\mathrm{AF} \\
\text { duration 3- } \\
48 \mathrm{~h}\end{array}$ & Amiodarone & $\begin{array}{l}\text { AF termination } \\
\text { within } 90 \mathrm{~min}\end{array}$ & $\begin{array}{l}53.4 \% \text { vs. } 5.2 \% \\
(p<0.0001)\end{array}$ & 11 \\
\hline
\end{tabular}

\section{Enhanced or facilitated electrical CV}

Enhanced or facilitated $\mathrm{CV}$ is the procedure of antiarrhythmic therapy before standart electrical CV. Pretreatment or repeat treatment with antiarrhythmic drugs such as ibutilide, amiodarone, sotalol, propafenone or flecainide increases the likelihood of restoration of SR and helps prevent recurrent AF. Enhanced efficacy may involve decreasing the energy required to achieve $\mathrm{CV}$, prolonging atrial refractory periods, and suppressing atrial ectopy that may cause early recurrence of AF [5, 6]. Although not without risk, the administration of antiarrhythmic drugs before electrical CV may have a beneficial effect on the different time-dependent types of CV outcomes. Shock failure can be prevented by ibutilide. In 100 patients with persistent AF, placebo and intravenous ibutilide, administered 10 min before electrical CV were compared. Electrical CV had a $100 \%$ success rate in the ibutilide-pretreated patients compared to $72 \%$ in the placebo group. It is noteworthy that in all the patients in the placebo group in whom CV initially could not restore SR, resumption of SR was obtained when ibutilide was given before a second CV attempt [69]. The selection of the appropriate antiarrhythmic drug to be administered before the electrical CV depends not only on the type of the time-dependent recurrence but also on the presence of structural heart disease [5].

\section{Optimal cardioversion in ED? Electrical or pharmacological}

Rate control drugs were commonly used before CV became a standard procedure. Recent trial showed that use of rate control medication before electrical CV of recent-onset AF or $\mathrm{AFl}$ in the emergency department is associated with reduced success rates, but no effect on pharmacological CV [70]. The development of new drugs has increased the popularity of pharmacological $\mathrm{CV}$, but the disadvantages include the risk of drug-induced torsades de pointes or other serious arrhythmias. Moreover, pharmacological CV is less effective than direct-current $\mathrm{CV}$ when biphasic shocks are used. The disadvantage of electrical CV is that it requires conscious sedation or anesthesia, which pharmacological CV does not. There is no evidence that the risk of thromboembolism or stroke differs between pharmacological and electrical methods of $\mathrm{CV}$. The recommendations for anticoagulation are therefore the same for both methods $[5,6]$.

\section{Is cardioversion feasible?}

The chances of restoring and maintaining SR are inversely related to the duration of AF. $\mathrm{CV}$ may not usually be attempted if patients have been in persistent AF for more than 1-2 years. The other major predictor of failure is relapse to $\mathrm{AF}$ following previous $\mathrm{CVs}$, particularly if this has occurred despite maintenance antiarrhythmic drug therapy. By contrast, advanced age and structural heart disease are often said to be relative 
contraindications to $\mathrm{CV}$, although there is little objective evidence to suggest that the chances of success are markedly reduced by either. On the other side of the equation, the chances of success are beter with AF of short duration and particularly if there has been an acute precipitant that has resolved (e.g. pneumonia, general anaesthesia, etc.). In patients with structural heart disease (valvular, LV systolic dysfunction, LV hypertrophy, etc.), echocardiographic parameters may be considered before attempting CV (Table 6) $[5,30,33]$.

\section{Cardioversion resistant patient or immediate reccurent patient}

When electrical CV fails, shocks can be repeated at highest energy until the arrhythmia terminates or a decision is made to abandon electrical CV. Repositioning the paddles or trying other positions (anteroposterior or anterolateral) should also be done in case of failure. Furthermore, the double-paddle technique is another alternative as well as pharmacologic facilitated CV: In one study, patients who had AF and had failed 360-J monophasic CV were loaded with amiodarone orally. If repeat 360-J monophasic CV persisted in failing, the patients underwent the double-paddle technique: Two monophasic defibrillators were used with two sets of paddles for each patient; each defibrillator was set for a synchronous shock at the maximum output of $360 \mathrm{~J}$; they then were discharged simultaneously, resulting in successful conversion of 13 out of 15 patients [71]. Energy waveform should be changed to biphasic if it is monophasic. Biphasic waveforms may be of special interest in patients who have failed to revert with the use of monophasic waveforms [72].

Some rate control drugs (e.g verapamil) may be considered in addition to fascilitated electrical CV, because of their enhancement effect also. If echocardiography is not performed, should be performed to rule out significant atrial enlargement or severe valve diseases. Etiologies of AF should be rechecked. After failure of repeated attemps, CV strategy should be abandoned and rate control startegy should be accepted.

\section{Should adjunctive antiarrhythmic drugs be used for maintenance therapy?}

Overall, 70-80\% of patients revert to AF within 12 months following successful CV if no antiarrhythmic treatment is prescribed. The chances of relapse can be reduced by drug treatment. Amiodarone is the most commonly used drug. However, even amiodarone only reduces the chance of recurrent AF to $20-30 \%$ by the end of the first year. Class I agents (flecainide, propafenone, etc.) are seldom prescribed for this purpose in the light of mounting evidence that they increase cardiac mortality, particularly among patients with ischaemic heart disease and heart failure. Dronadarone can be used in the presence of left ventricular hypertrophy, coronary heart disease but not in heart failure. Echocardiography should be performed before deciding which antiarrhythmic drug for rhythm maintenance therapy $[5,6,20]$.

\section{Thromboprophylaxis in pericardioversion period}

The pro-embolic tendency increases markedly after $\mathrm{CV}$, be it spontaneous, pharmacological or electrical, especially when the period of AF before $\mathrm{CV}$ is prolonged $[23,24]$. After CV, risk of thrombo-embolism due to post-CV left atrial/LAA dysfunction (so-called 'atrial stunning') persists up to 3 months [25]. Thromboembolic events have been reported in about $3 \%$ to $5 \%$ of patients who did not receive anticoagulation before $\mathrm{CV}$, whereas it is only $0 \%$ to $1 \%$ by adequate anticoagulation or by exclusion of left atrium thrombus before the procedure $[59,60]$.

Planning of adequate thromboprophylaxis pre-CV and post-CV is crucial to prevent embolic events. Thromboproplyaxis with heparin (unfractionated heparin or LMWH) should be given before electrical or pharmacological $\mathrm{CV}$ in patients with recent-onset AF within $48 \mathrm{~h}$ of onset or over $48 \mathrm{~h}$ if thrombus exluded at TOE $[5,6,20]$. If unfractionated heparin is chosen, therapeutic range for the aPTT should be kept between 1.5 to 2.5 times of the normal value. Unfractionated heparin has rapid onset advantage over LMWH. 
Intravenous LMWH has more rapid onset of action than subcutaneous (sc) LMWH. Enoxaparin activity, as measured by anti-Xa levels, achieves peak effect within 10 minutes of an iv injection, irrespective of whether patients are receiving additional medications. For an enoxaparin dose of $1 \mathrm{mg} / \mathrm{kg}$ iv, the time to subtherapeutic levels is 4 hours [73]. After a sc injection of enoxaparin, the peak time to effective anticoagulation is delayed such that maximum anti-Xa activity levels are not seen until 3-5 hours after drug administration [74]. So, if rapid onset of anticoagulation is desired, either UFH iv or LMWH iv should be given. After CV if one of VKAs is chosen, UFH or LMWH should be continued until INR level reached 2.0-3.0. If dabigatran is chosen for anticoagulation, dabigatran should be initiated 1-2 hours before planned dose of heparin. After CV VKA or dabigatran should be continued for 4 weeks post-CV. After 4 weeks, long term anticoagulation should be planned through the patient's risk factor for thromboembolism (Table 2) [20,69]. In patients with valvular AF INR should be in recommended range (Table 4). If not, LMWH or UFH should be administered pre-CV and continued untill target INR reached. Value of rivaroxaban and apixaban in CV period has not yet well established.

\section{Conclusion}

$\mathrm{AF}$ remains the most common arrhythmia requiring treatment in the ED and is the cause of major morbidity and considerable financial burden. Choosing the appropriate therapy to treat recent-onset AF can be extremely demanding and problematic and recent efforts have been focused on identification of an iv anti-arrhythmic drug that can provide rapid, effective and safe CV of an acute episode. While the currently available antiarrhythmics show moderate efficacy and pose a risk for serious ventricular proarrhythmias, vernakalant, a recently developed relatively atrial-selective multi-channel inhibitor, has consistently proved to be both effective and safe in converting recent-onset AF to SR in randomized clinical trials. Its relatively high atrial selectivity preventing potentially lethal episodes of torsades de pointes as well as its prompt onset of action, offer iv vernakalant a strong advantage over its competitors and constitutes an attractive option for the physician.

Rapid intervention to recent-onset $\mathrm{AF}$ is an other important issue in term of preventing structural changes in left atrium thereby persistence of AF. Although long term efficacy of antiarrhyhmic drugs in maintenance of SR after CV is not much satisfactory. Combination of advances in catheter based therapies and antiarrhythmic drugs for $\mathrm{AF}$ seems to fill our expectectations.

\section{References}

1. Zarifis J, Beevers G, Lip GY. Acute admissions with atrial fibrillation in a British multiracial hospital population. Br J Clin Pract 1997; 51: 91-6.

2. Lip GY, Tean KN, Dunn FG. Treatment of atrial fibrillation in a district general hospital. Br Heart J 1994; 71: 92-5.

3. Stewart FM, Singh Y, Persson S. Atrial fibrillation: Prevalence and management in an acute general medical unit. Aust N Z J Med 1999; 29: 51-8.

4. Laguna P, Martín A, Del Arco, Gargantilla P, on behalf of the GEFAUR-1 investigators. Risk factors for stroke and thromboprophylaxis in atrial fibrillation: What happens in daily clinical practice? The GEFAUR-1 study. Ann Emerg Med 2004; 44: 3-11.

5. Fuster V, Ryden LE, Cannom DS. ACC/AHA/ESC 2006 guidelines for the management of patients with atrial fibrillation. J Am Coll Card 2006; 48: 149246.

6. Camm AJ, Kirchhof P, Lip GYP. ESC 2010 guidelines for the management of patients with atrial fibrillation. Eur Heart J 2010; 31: 2369-429.

7. Gillis AM, Verma A, Talajic M. Canadian Cardiovascular Society atrial fibrillation guidelines 2010: Rate and rhythm management. Can J Cardiol 2011; 
27: 47-59.

8. The National collaborating centre for chronic conditions. Atrial fibrillation: National clinical guideline for management in primary and secondary care. London: Royal College of Physicians (UK); 2006: www.nice.org.uk (Erişim tarihi: 21. 05. 2014).

9. Wyse DG, Waldo AL, DiMarco JP. Atrial Fibrillation Follow-up Investigation of Rhythm Management (AFFIRM) Investigators. A comparison of rate control and rhythm control in patients with atrial fibrillation. N Engl J Med 2002; 347: 182533.

10. Roy D, Talajic M, Nattel S. Rhythm control versus rate control for atrial fibrillation and heart failure. N Engl J Med 2008; 358: 2667-77.

11. Buccelletti F, Di Somma S, Galante A. Disparities in management of new-onset atrial fibrillation in the emergency department despite adherence to the current guidelines: Data from a large metropolitan area. Intern Emerg Med 2011; 6: 14956.

12. Rogenstein C, Kelly AM, Mason S. An international view of how recent-onset atrial fibrillation is treated in the emergency department. Acad Emerg Med 2012; 19: 1255-60.

13. Stiell IG, Clement CM, Brison RJ. Variation in management of recent-onset atrial fibrillation and flutter among academic hospital emergency departments. Ann Emerg Med 2011; 57: 13-21.

14. delArco C, Martín A, Laguna P. Investigators in the Spanish Atrial Fibrillation in Emergency Medicine Study Group (GEFAUR). Analysis of current management of atrial fibrillation in the acute setting: GEFAUR-1 study. Ann Emerg Med 2005; 46: 424-30.

15. Zimetbaum P, Ho KK, Olshansky B. Variation in the utilization of antiarrhythmic drugs in patients with new-onset atrial fibrillation. Am J Cardiol 2003; 91: 81-3.

16. Laguna P, Martín A, Del Arco C. Spanish Atrial Fibrillation in Emergency Medicine Study Group (GEFAUR-2). Differences among clinical classification schemes for predicting stroke in atrial fibrillation: Implications for therapy in daily practice. Acad Emerg Med 2005; 12: 828-34.

17. Arendts G, Krishnaraj M, Paull G, Rees D. Management of atrial fibrillation in the acute setting-findings from an Australasian survey. Heart Lung Circ 2010; 19: 423-7.

18. Stiell IG, Macle L; CCS Atrial Fibrillation Guidelines Committee. Canadian Cardiovascular Society atrial fibrillation guidelines 2010: Management of recentonset atrial fibrillation and flutter in the emergency department. Can J Cardiol 2011; 27: 38-46.

19. Martinez AM, Lozano IF, Puig BCV. Atrial fibrillation management in the hospital emergency department: 2012 update. Emergencias 2012; 24: 300-324.

20. Camm AJ, Lip GY, De Caterina R. 2012 focused update of the ESC Guidelines for the management of atrial fibrillation: An update of the 2010 ESC Guidelines for the management of atrial fibrillation. Eur Heart J 2012; 33: 2719-47.

21. Vahanian A, Alfieri O, Andreotti F. Guidelines on the management of valvular heart disease (version 2012): Joint Task Force on the Management of Valvular Heart Disease of the European Society of Cardiology (ESC); European Association for Cardio-Thoracic Surgery (EACTS). Eur Heart J 2012; 33: 245196.

22. Bonow RO, Carabello BA, Chatterjee K. 2008 Focused update incorporated into the ACC/AHA 2006 guidelines for the management of patients with valvular heart disease: A report of the American College of Cardiology/American Heart Association Task Force on Practice Guidelines. Circulation 2008; 118: 523-661.

23. Sohara H, Amitani S, Kurose M, Miyahara K. Atrial fibrillation activates platelets and coagulation in a time-dependent manner: A study in patients with paroxismal atrial fibrillation. J Am Coll Cardiol 1997; 29: 106-12. 
24. Sparks PB, Jayaprakash S. Left atrial mechanical function after brief duration atrial fibrillation. J Am Coll Cardiol 1999; 33: 342-9.

25. Choi JI, Park SM, Park JS. Changes in left atrial structure and function after catheter ablation and electrical cardioversion for atrial fibrillation Circ J. 2008; 72: 2051-7.

26. Wakai A, O'Neill JO. Emergency management of atrial fibrillation. Postgrad Med J. 2003; 79: 313-9.

27. Whitbeck MG, Charnigo RJ, Khairy P. Increased mortality among patients taking digoxin-analysis from the AFFIRM study. Eur Heart J 2012: 10; 1093.

28. Siddoway LA. Amiodarone: Guidelines for use and monitoring. Am Fam Physician 2003; 68: 2189-97.

29. Marchese P, Bursi F, Delle Donne G. Indexed left atrial volume predicts the recurrence of non-valvular atrial fibrillation after successful cardioversion. Eur $\mathbf{J}$ Echocardiogr 2011; 12: 214-21.

30. Providência R, Bara S, Paiva L. The role of echocardiography as a predictor of the incidence and progression of atrial fibrillation. J Atr Fibrillation 2012; 5: 2736.

31. Marchese P, Malavasi V, Rossi L. Indexed left atrial volume is superior to left atrial diameter in predicting nonvalvular atrial fibrillation recurrence after successful cardioversion: A prospective study. Echocardiography 2012; 29: 27684.

32. Frick M, Frykman V, Jensen-Urstad M. Factors predicting success rate and recurrence of atrial fibrillation after first electrical cardioversion in patients with persistent atrial fibrillation. Clinical Cardiology 2001; 24: 238-44.

33. Ben Khalfallah A, Sanaa I. Echocardiographic factors predictive of restoration and maintenance of sinus rhythm after reduction of atrial fibrillation. Arch Mal Coeur Vaiss 2007; 100: 745-52.

34. Antonielli E, Pizzuti A, Pálinkás A. Clinical value of left atrial appendage flow for prediction of long-term sinus rhythm maintenance in patients with nonvalvular atrial fibrillation. J Am Coll Cardiol 2002; 39: 1443-9.

35. Okçün B, Yigit Z, Küçükoglu MS, Mutlu H, Sansoy V, Güzelsoy D, Uner S. Predictors for maintenance of sinus rhythm after cardioversion in patients with nonvalvular atrial fibrillation. Echocardiography 2002; 19: 351-7.

36. Wang T, Wang M, Fung JW, Yip. Atrial strain rate echocardiography can predict success or failure of cardioversion for atrial fibrillation: A combined transthoracic tissue Doppler and transoesophageal imaging study. Int J Cardiol 2007; 114: 202-9.

37. Lucà $\mathrm{F}$, LaMeir M, Rao CM. Pharmacological management of atrial fibrillation: One, none, one hundred thousand. Cardiol Res Pract 2011; 874802.

38. Nair M, George LK, Kosby SKG. Safety and efficacy of ibutilide in cardioversion of atrial flutter and fibrillation. J Am Board Fam Med 2011; 24: 86 92.

39. Bronis K, Metaxa S, Koulouris S, Manolis AS. Vernakalant: Review of a novel atrial selective antiarrhythmic agent and its place in current treatment of atrial fibrillation. Hospital chronicles 2012; 7: 171-81.

40. Wakai A, O'Neill JO. Emergency management of atrial fibrillation. Postgrad Med J 2003; 79: 313-9.

41. Fuster V, Rydén LE, Asinger RW. ACC/AHA/ESCguidelines for the management of patients with atrial fibrillation. Eur Heart J 2001; 22: 1852-923.

42. Charles DD. European resuscitation council guidelines for resuscitation 2010, Section 4: Adult advanced life support. Resuscitation 2010; 81: 1305-52.

43. Nolan JP. European resuscitation council guidelines for resuscitation 2010, Section 1: Executive summary. Resuscitation 2010; 81: 1219-76.

44. Pitcher D, Perkins G. Peri-arrest arrhythmias. In: Nolan JP, ed. Resuscitation guidelines 2010.1st ed. London: Resuscitation Council 2010; 81-9. 
45. Deakin C, Nolan J, Perkins G, Lockey A. Adult advanced life support. In: Nolan JP, ed. Resuscitation guidelines 2010.1st ed. London: Resuscitation Council 2010; 58-80.

46. Morrison LJ. Part 8: Advanced life support: 2010 International consensus on cardiopulmonary resuscitation and emergency cardiovascular care science with treatment recommendations. Circulation 2010; 122: 345-421.

47. Wann LS, Curtis AB, January CT. 2011 ACCF/AHA/HRS focused update on the management of patients with atrial fibrillation (updating the 2006 guideline): A report of the American College of Cardiology Foundation/American Heart Association Task Force on Practice Guidelines. Circulation 2011; 123: 104-23.

48. Gallagher MM, Guo XH, Poloniecki JD. Initial energy sitting, outcome and efficiency in direct current cardioversion of atrial fibrillation. J Am Coll Cardiol 2001; 38: 1498-504.

49. Lundstrom T, Ryden L. Chronic atrial fibrillation: Long term results of direct current cardioversion. Acta Med Scand 1988; 223: 53-9.

50. Lown B. Electrical reversion of cardiac arrhythmias. Br Heart J 1967; 29: 469-89.

51. Dalzell GW, Anderson J, Adgey AA. Factors determining success and energy requirement for cardioversion of atrial fibrillation. Q J Med 1990; 76: 903-13.

52. Dittrich HC, Erikson JS, Schneideman T. Echocardiographic and clinical predictors for outcome of elective cardioversion of atrial fibrillation. Am J Cardiol 1989; 63: 193-7.

53. Gallagher MM, Guo XH, Poloniecki JD. Initial energy setting, outcome and efficiency in direct current cardioversion of atrial fibrillation and flutter. J Am Coll Cardiol 2001; 38: 1498-504.

54. Mittal S, SteMittal S, Stein KM. An update on electrical cardioversion of atrial fibrillation. Card Electrophysiol Rev 2003; 7: 285-9.

55. Gall NP, Murgatroyd FD. Electrical cardioversion for AF-the state of the art. Pacing Clin Electrophysiol 2007; 30: 554-67.

56. Lesser MF. Safety and efficacy of in-office cardioversion for treatment of supraventricular arrhythmias. Am J Cardiol 1990; 66: 1267-8.

57. Khaykin Y, Newman D, Kowalewski M, Korley V, Dorian P. Biphasic versus monophasic cardioversion in shock-resistant atrial fibrillation. J Cardiovasc Electrophysiol 2003; 14: 868-72.

58. Deakin CD, Ambler JJ. Post-shock myocardial stunning: A prospective randomised double-blind comparison of monophasic and biphasic waveforms. Resuscitation 2006; 68: 329-33.

59. Bjerkeland CI, Orning OM. The efficacy of anticoagulant therapy in preventing embolism related to DC electrical conversion of atrial fibrillation. Am J Cardiol 1969; 23: 208-16.

60. Arnold AZ, Mick MJ, Mazurck RP, Loop FD, Trohman RG. Role of prophylactic anticoagulation for direct current cardioversion in patients with atrial fibrillation or atrial flutter. J Am Coll Cardiol 1992; 19: 851-55.

61. Chevalier P, Durand-Dubief A, Burri H. Amiodarone versus placebo and classic drugs for cardioversion of recent-onset atrial fibrillation: A meta-analysis. J Am Coll Cardiol 2003; 41: 255-62.

62. Schilling RJ. Cardioversion of atrial fibrillation: The use of antiarrhythmic drugs. Heart 2010; 96: 333-8.

63. Roy D, Rowe BH, Stiell IG. CRAFT Investigators. A randomized, controlled trial of RSD 1235, a novel anti-arrhythmic agent, in the treatment of recent onset atrial fibrillation. J Am Coll Cardiol 2004; 44: 2355-61.

64. McBride B. The emerging role of antiarrhythmic compounds with atrial selectivity in the management of atrial fibrillation. J Clin Pharmacol 2009; 49: 258-67.

65. Roy D, Pratt CM, Torp-Petersen C. Vernakalant hydrochloride for rapid conversion of atrial fibrillation-A phase 3, randomized, placebo-controlled trial. 
Circulation 2008; 117: 1518-25.

66. Kowey PR, Dorian P, Mitchell LB. Vernakalant hydrochloride for the rapid conversion of atrial fibrillation after cardiac surgery- A randomized, doubleblind, placebo-controlled trial. Circ Arrhythm Electrophysiol 2009; 2: 652-9.

67. Pratt CM, Roy D, Torp-Petersen C. Usefulness of vernakalant hydrochloride injection for rapid conversion of atrial fibrillation. Am J Cardiol 2010; 106: 127783.

68. Stiell IG, Dickinson G, Butterfield NN. Vernakalant hydrochloride: A novel atrial-selective agent for the cardioversion of recent-onset atrial fibrillation in the emergency department. Acad Emer Med 2010; 17: 1175-82.

69. Oral H, Souza JJ, Michaud GF. Facilitating transthoracic cardioversion of atrial fibrillation with ibutilide pretreatment. N Engl J Med 1999; 340: 1849-54.

70. Blecher GE, Stiell IG, Rowe BH. Use of rate control medication before cardioversion of recent-onset atrial fibrillation or flutter in the emergency department is associated with reduced success rates.CJEM 2012; 14: 169-77.

71. Kabukcu M, Demircioglu F, Yanik E. Simultaneous double external DC shock technique for refractory atrial fibrillation in concomitant heart disease. Jpn Heart J 2004; 45: 929-36.

72. Khaykin Y, Newman D, Kowalewski M. Biphasic versus monophasic cardioversion in shock-resistant atrial fibrillation. Cardiovasc Electrophysiol 2003; 14: 868-72.

73. Zalc S, Lemos PA, Esteves A. Early ambulation and variability in anticoagulation during elective coronary stenting with a single intravenous bolus of low-dose, low-molecular weight heparin enoxaparin. J Invasive Cardiol 2006; 18: 45-8.

74. Collet JP, Montalescot G, Lison L. Percutaneous coronary intervention after subcutaneous enoxaparin pretreatment in patients with unstable angina pectoris. Circulation 2001; 103: 658-63.

75. Nagarakanti R, Ezekowitz MD, Oldgren J. Dabigatran versus warfarin in patients with atrial fibrillation: An analysis of patients undergoing cardioversion. Circulation 2011; 123: 131-6. 